San Jose State University

SJSU ScholarWorks

Master's Theses

Master's Theses and Graduate Research

Fall 2017

\title{
Effect of Land Use Types on the Distribution of Carnivore Species in Santa Clara County, CA.
}

Logan Thompson

San Jose State University

Follow this and additional works at: https://scholarworks.sjsu.edu/etd_theses

\section{Recommended Citation}

Thompson, Logan, "Effect of Land Use Types on the Distribution of Carnivore Species in Santa Clara County, CA." (2017). Master's Theses. 4887.

DOI: https://doi.org/10.31979/etd.e944-jx6p

https://scholarworks.sjsu.edu/etd_theses/4887

This Thesis is brought to you for free and open access by the Master's Theses and Graduate Research at SJSU ScholarWorks. It has been accepted for inclusion in Master's Theses by an authorized administrator of SJSU ScholarWorks. For more information, please contact scholarworks@sjsu.edu. 


\title{
EFFECT OF LAND USE TYPES ON THE DISTRIBUTION OF CARNIVORE SPECIES IN SANTA CLARA COUNTY, CA.
}

\author{
A Thesis \\ Presented to \\ The Faculty of the Department of Environmental Studies \\ San José State University \\ In Partial Fulfillment \\ of the Requirements for the Degree \\ Master of Science
}

by

Logan Thompson

December, 2017 
(C) 2017

Logan Thompson

ALL RIGHTS RESERVED 
The Designated Thesis Committee Approves the Thesis Titled

EFFECT OF LAND USE TYPES ON THE DISTRIBUTION OF CARNIVORE SPECIES IN SANTA CLARA COUNTY, CA.

\author{
by \\ Logan Thompson \\ APPROVED FOR THE DEPARTMENT OF ENVIRONMENTAL STUDIES
}

SAN JOSÉ STATE UNIVERSITY

December, 2017

Lynne Trulio, Ph.D. Department of Environmental Studies

Stephanie Trewhitt, M.S. Department of Biological Sciences

William Russell, Ph.D. Department of Environmental Studies 


\title{
ABSTRACT \\ EFFECT OF LAND USE TYPES ON THE DISTRIBUTION OF CARNIVORE SPECIES IN SANTA CLARA COUNTY, CA.
}

\author{
by Logan Thompson
}

Anthropogenic pressures such as habitat loss and hunting pressures have caused terrestrial mammalian carnivores to decline by $95-99 \%$ in many regions of the world. These species are especially susceptible to fragmented habitats and a diminishing food supply because of their slow reproductive rates and high metabolic demands. In biodiversity hotspots such as California, understanding the range of human impacts to species is critical. This project assessed carnivore species distribution and occupancy by placing remote camera traps in a protected Reserve, agricultural, and developed land use types. Mountain lions were only detected in the protected Reserve, and because of this coyotes and bobcats became the dominant predator species in the developed and agricultural land cover types. Coyotes and grey foxes exhibited forms of spatial and temporal niche partitioning to avoid the presence of mountain lions. These activity shifts between competing species has unknown effects on both the carnivore community and the ecosystem as a whole. All carnivore species, with the exception for opossums and skunks, were sampled more often in the mixed riparian forest habitat over any other habitat type. This indicates that human modified landscapes alter carnivore community structures both directly and indirectly. Wildlife biologists and conservationists can use this information to better manage for the coexistence of both carnivore communities and human populations. 


\section{DEDICATION}

I would like to thank my Thesis Advisor, Dr. Lynne Trulio for all of her help throughout this process, without her guidance and support this would not have been possible. I would also like to thank my Thesis Committee members Dr. Will Russell and Professor Stephanie Trewhitt for their encouragement, assistance and sound recommendations both academically and in the field.

I am very appreciative of Bob Clement, Henry Coletto, and the California Department of Fish and Wildlife for allowing me to access the Canada De Los Osos Ecological Reserve and providing me with the tools and support to make this research project a reality.

Finally I would like to thank my girlfriend Briana, my parents Rick and Barb, and my brother Ryan for always being there and supporting me throughout this process, I am very grateful to have all of you in my life.

"If you know wilderness in the way that you know love, you would be unwilling to let it go.... This is the story of our past and it will be the story of our future". (Terry Tempest Williams) 


\section{TABLE OF CONTENTS}

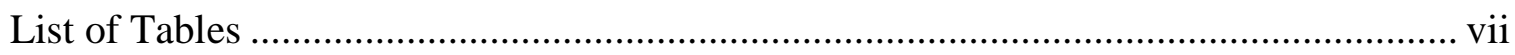

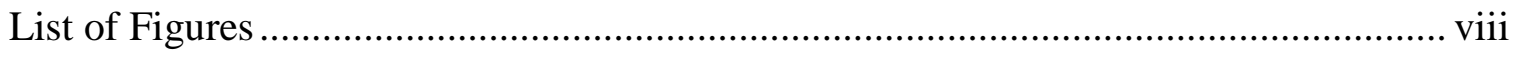

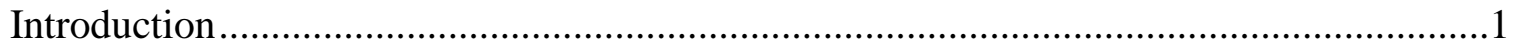

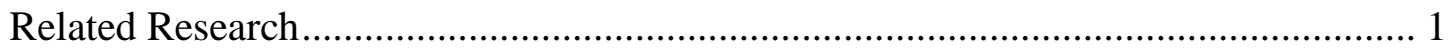

Top down trophic cascades ........................................................................

Mesopredator release hypothesis ...................................................................6

Niche Partitioning …….............................................................................

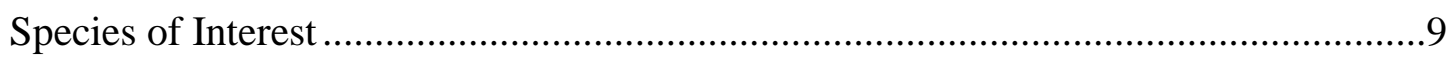

Research Questions and Hypotheses .....................................................................12

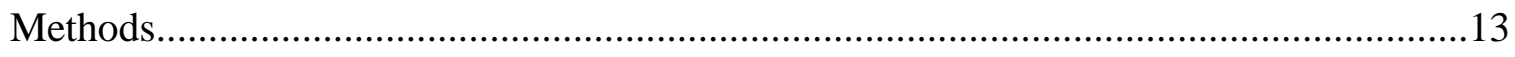

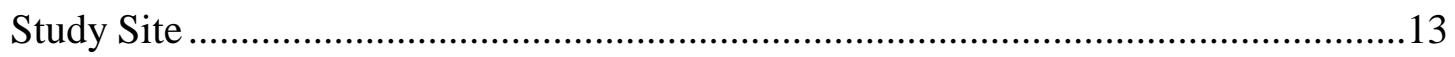

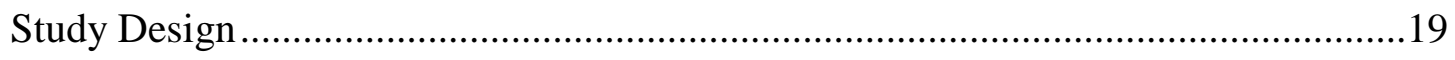

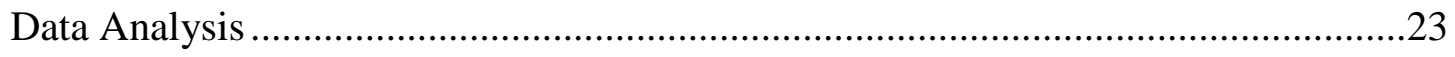

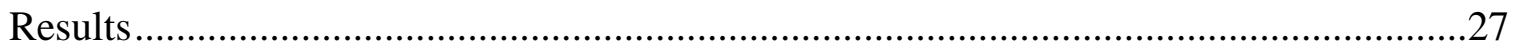

Species and Land Use Types ................................................................................26

Activity Times for Each Species............................................................................

Land Use Types' Affect on Mesopredator Species .....................................................40

Mesopredators Response to the Presence of Top Predators ...........................................40

Preferred Habitat Preferences for Each Carnivore Species ..........................................41

All Terrestrial Mammalian Species Detected ...............................................................42

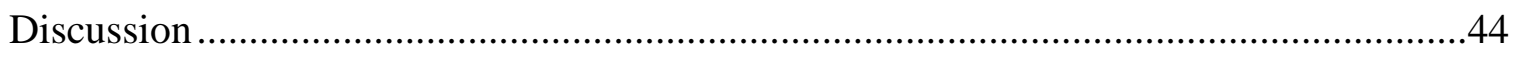

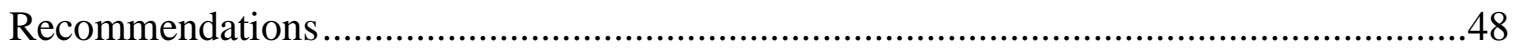

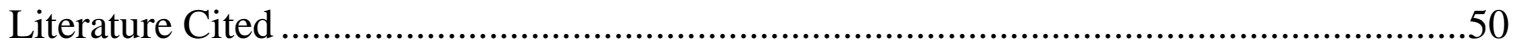




\section{LIST OF TABLES}

Table 1. Habitat Preferences of Each Species ..............................................................41

Table 2. Total Detections for all Mammalian Species Detected in Each Land Use Type 


\section{LIST OF FIGURES}

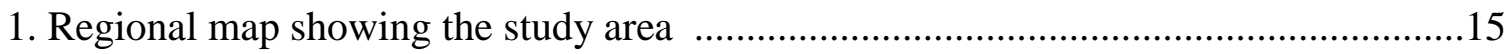

2. Camera station used in the urban land use in Morgan Hill, CA .................................16

3. Camera station used in the agricultural land use in Gilroy, CA .................................17

4. Camera station used in the "Reserve" land use type ..............................................19

5. Transect design of all three land use types with camera set up ...............................21

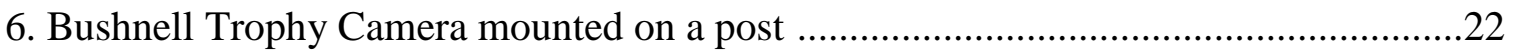

7. Bushnell Trophy Camera mounted on a tree …..................................................23

8. Frequency/24 hour period of coyotes and bobcats within each land use type .............28

9. Frequency/24 hour period of grey fox within each land use type .............................29

10. Frequency/24 hour period of raccoons, skunks, opossums within each land

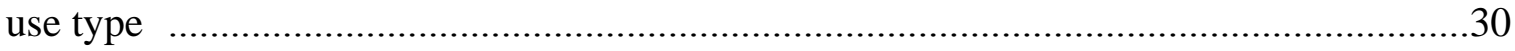

11. Frequency/24 period of cats and dogs within each land use type ............................31

12. Mountain lion temporal activity patterns in the Reserve ......................................32

13. Coyote temporal activity patterns within each land use type ..................................33

14. Bobcat temporal activity patterns within each land use type .................................34

15. Grey Fox temporal activity patterns within each land use type .............................35

16. Skunk temporal activity patterns within each land use type ..................................36

17. Opossum temporal activity patterns within each land use type ..............................37

18. Raccoon temporal activity patterns within each land use type ...............................38

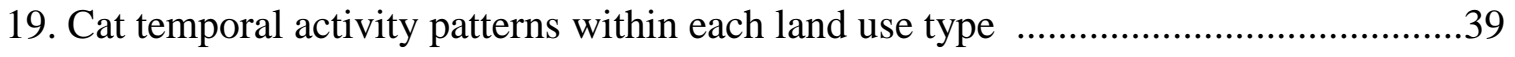

20. Dog temporal activity patterns within each land use type ....................................40 


\section{Introduction}

As the human population continues to grow, wildlife habitat is destroyed and fragmented because of water diversion, mining, logging, urban development, and agriculture. These anthropocentric impacts have caused many species' populations to become severely depleted or extinct (Crooks et al., 2011). Current science indicates that we are in the midst of the sixth great extinction of species, which can be directly attributed to human activities such as habitat loss, hunting pressures, climate change, the introduction of exotic species, and disease (International Union for Conservation and Nature, 2015). Humans are essentially driving many species to extinction faster than species can adapt.

Carnivore species are especially susceptible to habitat loss and hunting pressures because they typically occur at low densities and have slow population growth rates (Ripple, Estes, Robert, Beschta, \& Wilmers, 2014). They also require large areas of land to hunt and reproduce, which often puts them in close contact with humans and livestock (Crooks, Burdett, Theobald, Rondinini, \& Boitani, 2011). In the past two centuries, predatory species have seen a major decline in both population numbers and diversity

with terrestrial mammalian carnivores declining by 95-99\% in many regions of the world (Berger, Stacey, Bellis, \& Johnson, 2001).

\section{Related Research}

Carnivores are important from an ecological point of view because of their contribution to maintaining biodiversity and ecosystem functions. They structure wildlife communities both directly and indirectly through complex ecosystem processes. Their 
predation on other species has ripple down effects which plays a key role in their environment and gives them great ecological value. Terborgh (1999), wrote, “Top-down means that species occupying the highest trophic level (top carnivores) exert a controlling influence on species at the next lower level (their prey) and so forth down the trophic ladder." The pressure carnivores place on herbivore species allow trees and plants to flourish which can enhance carbon storage (Ripple and Beschta, 2006). Carnivores also tend to select prey species that are weak and diseased naturally helping to remove an infected animal from a healthy population. This process helps stop the spread of disease (Packer et al., 2003). Some of the larger carnivore species are considered apex predators; these species are especially valuable to their ecological communities because of their role in trophic cascades, and their ability to have disproportionately large effects on ecosystems relative to their abundance.

Throughout history large carnivores have been both revered and despised by humans. They have brought on feelings of fear, admiration, fascination, and wonder to people, which is unique when compared to any other wildlife group (Gehrt et al., 2010). However, most carnivore species are considered as vermin or as agricultural pests that should be killed or harvested for their fur (Roemer, Gompper, \& Valkenburgh, 2009). When European settlers first arrived in the United States, they regarded carnivore species as threats to their livestock, competition for game species, and hunted them for their fur.

The desire to control and dominate nature is just one of the reasons why humans have historically ignored the ecological benefits that carnivore species can provide. Many wildlife agencies have also traditionally employed "bottom-up" control strategies to 
manage the biodiversity and abundance of wildlife ecosystems. The bottom-up approach states that energy is maintained by lower trophic levels, such as plants and herbivores, and moves upward to higher trophic levels. This system has allowed governmental agencies to place little ecological utility on carnivore species which has allowed wildlife managers to persecute and often eliminate them altogether (Miller et al., 2001).

Carnivore species still face many of the same challenges and stigmas that they did hundreds of years ago, and in many cases they are worse off now because they have less available habitat and lower abundances of prey species. However, within the past few decades there has been significant public outcry over the decimation of many of our mammalian carnivore species. In 1973, the Congress of the United States enacted the Endangered Species Act, which recognized that endangered and threatened wildlife and plant species "are of esthetic, ecological, educational, historical, recreational, and scientific value to the Nation and its people." This law protects legally designated endangered and threatened species, including predators.

The rapid increase of the human population in the last 200 years has drastically altered wildlife landscapes all around the world. The increasing human demand for more food and natural resources has eroded and fragmented wildlife habitats all around the world (Karanth \& Chellam, 2009). Habitat loss is one of the major reasons that species, including carnivores, are struggling to survive today. Ceballos \& Ehrlich (2002) found that the global distribution of 173 mammals had collectively lost over $50 \%$ of their historic ranges in the last 200 years. If an animal does not have the necessary habitat to subsist and reproduce, the species will inevitably become extirpated or extinct. 
Fragmented areas pose an even greater challenge to wide-ranging carnivore species because of their large spatial requirements for adequate habitat for hunting, and reproduction (Noss, Quigley, Hornocker, Merrill, \& Paquet, 1996). Large-bodied terrestrial carnivores isolated in a habitat patch are restricted in their ability to connect to other habitat patches, which can lead to a decrease in reproduction and genetic diversity.

In addition to habitat loss, hunting pressure has also played a major role in the loss of carnivore species biodiversity and abundance. There has always been a general fear and intolerance of carnivore species by farmers and ranchers which has created a great deal of conflict between large predators and humans. Rural areas with open rangelands have traditionally been a place where carnivores have access to available prey species, and where people with livestock are often found (Zimmermann et al., 2009). When large carnivores come into close contact with livestock, the ranchers are frequently threatened by the potential threat of these species. Carnivores will seek alternative sources of food, such as a rancher's vulnerable livestock. This often leads to depredation as a means of carnivore management, which has historically been the standard protocol for many governmental agencies when dealing with wide ranging predators, which has contributed to their decline. According to the United States Department of Agriculture Wildlife Services (2008), their organization kills over 120,000 native carnivores each year, primarily to appease livestock operations.

Top down trophic cascades. Significant research shows the importance of "top down" regulation of ecosystems by large carnivores (Miller et al., 2001, Oswald et al., 1997, Terborgh et al., 1999). “Top down” trophic cascades occur when apex predators 
help to control a food web by maintaining the population of lower level consumers, which ultimately helps primary producers flourish. In modern America, Aldo Leopold recognized the intricate role that large carnivores play in an ecosystem. In the 1930s and 1940s, Leopold recognized the role that wolves and other apex predators played in forest and range ecosystems, via trophic cascades (Ripple \& Beschta, 2005). This knowledge and understanding of the influence that large predators have on their ecosystems has largely been ignored throughout history and has only recently been accepted by the scientific community.

One example of an apex predator that has had top down trophic cascading effects on its environment is the mountain lion (Felis concolor). Ripple and Beschta (2006) found that an increase in human visitors to Zion National Park caused a decline in mountain lion densities, leading to an increase in the mule deer population. The expanded deer population increased browsing suppression on native plant and tree species. This process ultimately led to the erosion of various bank streams and channels within the park. The reduced densities of mountain lions in the park also led to a decrease in aquatic and terrestrial species richness and abundance. Thus, the mountain lion, as a top predator, played a vital role in maintaining the biodiversity of plants and animals within the protected National Park.

One well-documented example of a top down trophic cascade is the reintroduction of grey wolves (Canis lupus) to Yellowstone National Park in 1995. The wolves were nonexistent in the park for 70 years and the result was that the elk and coyote populations increased dramatically, which significantly impacted the wildlife habitat as well as the 
abiotic factors (water and soil). Without wolves the native woody plants and vegetation were reduced to almost nothing (Ripple \& Beschta, 2005). Wolves were reintroduced into the Yellowstone ecosystem, and that affected many other species within the park. The wolves altered the behavior of the elk by not allowing them to be stationary in one area for extended periods of time. This process helped to reduce the pressure elk placed on many tree and plant species (Miller et al., 2001). Tree and plant species were able to increase and survive for regeneration. The increased frequency of elk movement also helped to aerate the soils which allowed more grasses to grow in the park. The wolves helped to maintain a healthy ecosystem by altering the behavior of herbivores, and controlling the number of herbivores in the population. The presence of wolves also resulted in an increase in beaver (Castor canadensis) colonies, which heavily rely on the resurgence of the woody tree and plant species (Ripple \& Beschta, 2005). The reintroduction of wolves also altered the top of the Yellowstone food chain by replacing coyotes as the apex predator, which had a tremendous affect on a host of other species. This resulted in an increase in the biodiversity and abundance of other small mammalian species (Ripple \& Beschta, 2005).

Mesopredator release hypothesis. The loss or extinction of an apex predator from an ecosystem can facilitate the population "release" of smaller or mesopredators, an ecological process called the mesopredator release hypothesis. A mesopredator can be defined as a species that is one trophic level below apex predators or as any mid ranking predator in a food web, regardless of its size or taxonomy (Prugh et al., 2009). Mesopredator release, first coined by Soule et al. (1988), describes a process that results 
in smaller predators exhibiting an increase in distribution and abundance due to the release from predation and competition of the apex predator (Cove et al., 2012; Crooks \& Soule, 1999). The elevated number and activity of mesopredators can increase predation pressure on native prey species, which may lead to decreased biodiversity and population declines of small prey animals, and in some cases it can result in extinction (Courchamp, Langlais, \& Sugihara, 1999). Crooks and Soule (1999) examined the effects that an apex predator, coyotes, had on a fragmented landscape. This study showed that the absence of the coyote caused a sudden increase in mesopredator species distribution and abundance affecting the persistence and survival of their avian prey. Once the coyote was no longer a part of the ecosystem many smaller predators, such as gray foxes, raccoons, skunks, and domestic cats, were able to move around the landscape without any pressure of predation or competition from the coyote. The increase in mesopredators ultimately decimated many bird populations in the area.

Johnson, Isaac, \& Fisher (2007) found that Australia had lost over eighteen mammalian species in the last 200 years, which represents over half of all mammalian extinctions worldwide. One of the major reasons behind this was because European settlers had severely decimated the dingo (Canis lupus dingo) population. When the dingo population declined, there was a drastic increase in the density and abundance of non-invasive mesopredators, such as red foxes and feral cats, mesopredators that overwhelmed the local marsupial prey, triggering mass extinctions over much of the continent (Johnson et al., 2007). This research indicated that the dingo is an important apex predator, and is essential at maintaining the biodiversity of species in Australia. 
Another example of the mesopredator release hypothesis can be found in the Pacific Ocean via the pacific sleeper shark (Somniosus pacificus). Frid, Baker, \& Dill (2008) discovered that the sleeper shark controlled the population of one of their prey species, the harbor seal (Phoca vitulina). When the sleeper shark was removed from the seals' habitat, the seal was able to move into previously unavailable habitats that were rich with prey species, such as pacific herring (Clupea pallasii) and walleye Pollock (Theragra chalcogramma). Some prey species, such as the walleye Pollock (Theragra chalcogramma) prefer to share the same deep water habitat as the sleeper shark. When some smaller fish prey species were exposed to the mesopredator release of the harbor seal (Phoca vitulina), there was a dramatic decline in fish abundance and changes in the community structure of that ecosystem.

The presence of an apex predator can suppress mesopredators by both killing and instilling fear, causing the smaller predators to change their behavior (Ritchie \& Johnson, 2009). This pressure can lead mesopredators to choose less suitable land use, such as agricultural lands or developed environments, to avoid an apex predator which ultimately effects the distribution and abundance of a host of other wildlife species (Ritchie \& Johnson, 2009).

Niche partitioning. The competitive exclusion principle states that two ecologically similar species cannot coexist in the same ecological niche (Gause, 1934). Thus, in order for a guild of carnivore species to occupy similar habitats, some degree of niche or resource partitioning must occur. The theory of niche partitioning, first developed by Hutchinson (1957), states that natural selection will drive two competing species into 
different adaptations of morphology, resource use, and behavior to limit negative effects on fitness. Wang \& Macdonald (2009) stated that resource partitioning in a multicarnivore community can be achieved by a variety of factors such as "selection for prey species, sizes, foraging habits, activity patterns, use of space, and evolution of different anatomical adaptations for prey selection."

Carnivore guilds often use spatial and temporal niche partitioning to increase fitness, which promotes coexistence (Schuette et al., 2013). For example, African wild dogs (Lycaon pictus) and cheetahs (Acinonyx jubatus) avoid areas of high prey densities preferred by the competitively superior African lions (Panthera leo) and hyenas (Crocuta crocuta) (Creel \& Creel, 2002). A study by Schuette, Wagner, Wagner, \& Creel (2013) found that subordinate carnivore species used temporal niche partitioning to avoid apex predators that could injure or kill them, or possibly steal their food. In the same study, they found that the dominant carnivore species (lions and hyenas) were most active in the middle of the night. In contrast, smaller mesopredators such as the black-backed jackal, civet, wildcat, and genet were more active over a broader range of times, thus avoiding contact with the larger predators. Niche partitioning is not the only way species are able to coexist, however it is an important ecological principle that can increase biodiversity of competing species.

\section{Species of Interest}

In habitats that are increasingly dominated by human beings, carnivores are forced to share space and resources with species that they would not normally tolerate. Human development and activity are altering the ways carnivore species share resources. The 
species that will be studied in my research include mountain lion (Puma concolor), raccoons (Procyon lotor), striped skunks (Mephitis mephitis), coyotes (Canis latrans), bobcats (Lynx rufus), Virginia opossum (Didelphis virginiana), and grey foxes (Urocyon cinereoargenteus). If all species are present in one habitat type, the mountain lion would serve as the apex predator in that ecosystem, while all other carnivore species would be considered mesopredators. Virginia opossums are classified as omnivores, but I will be including them into my study because previous studies have included them as well (Bateman \& Fleming, 2012; Kelly \& Holub, 2008; Wang, Allen, \& Wilmers, 2015).

Carnivore species differ in their sensitivity to anthropogenic influences. Some mesopredators, such as raccoons and skunks, are more readily able to exploit anthropogenic resources, and have thrived in some human altered landscapes. This success may be attributed to the lack of dominant apex predators, and frequent easy access to human food sources (Crooks, 2002). Apex predators, such as mountain lions, can be particularly sensitive to human activities (Wang, 2014). The extirpation of top predators can release mesopredators and reduce the biodiversity of wildlife species within an ecosystem (Cove et al., 2012; Crooks \& Soule, 1999; Johnson et al. 2007). In addition, changing the structure of predator guilds can drastically alter ecological communities, which can cause lasting long term effects on food webs (Johnson et al., 2007; Ripple \& Beschta, 2006; Wang, 2014).

Urbanization has severely affected carnivore species biodiversity and abundance. Mammalian carnivores are vulnerable to habitat loss because their high metabolic demands require abundant prey and thus expansive habitats (Ripple et al., 2014). A 
recent study found that $61 \%$ of the world's largest carnivores are listed as threatened under the International Union for Conservation and Nature (Ripple et al., 2014). Furthermore, the same study found that $77 \%$ of all carnivore species are experiencing continued population declines (Ripple et al., 2014). Carnivore species can provide many benefits to their environment both directly and indirectly through complex ecological processes. However, these species have large habitat requirements and some are very elusive, which makes them very hard to study. There has been very little research conducted in the San Francisco Bay Area on how land use conversion has affected carnivore species and the affects it can have on their ecological communities. By understanding how apex predators and mesopredators respond to varying levels of anthropocentric pressures, we can better manage for the coexistence of both carnivore communities and human populations.

The purpose of this thesis research is to determine carnivore species diversity, occupancy and distribution, in proximity to developed, agricultural, and protected woodland areas in highly urbanized Santa Clara County, CA. To address this topic, I tested these research questions: 


\section{Research Questions and Hypotheses}

Research Questions:

1. What carnivore species are present in the developed, agricultural and Reserve land use types and how frequently does each species occur on camera?

2. What are the activity times for each carnivore species in each land use type?

3. Of the habitat types examined, which is preferred for each carnivore species?

4. What other terrestrial mammals are found in each land use type?

\section{Research Hypotheses:}

$\mathrm{H}_{0} 1$ : Land use type does not significantly affect the occupancy of mesopredator species. $\mathrm{H}_{0}$ 2: The presence of top carnivores does not significantly affect the occupancy of mesopredator species. 


\section{Methods}

\section{Study Site}

This study was conducted in the southern region of Santa Clara County, California within a warm Mediterranean climate. Summer temperatures average 31.11 degrees C, while winter temperatures hover around 15.55 degrees $C$. The study area Cañada de los Osos Ecological Reserve (CDLOER), Gilroy and Morgan Hill receive on average, 53.34 cm of rainfall a year on average (National Oceanic and Atmospheric Administration, 2014) and has an elevation that ranges from 60-610 meters. Specifically, this study occurred in an ecological reserve (the Reserve), Cañada de los Osos Ecological Reserve, as well as the agricultural and urban environments to the west of the Reserve, which included the cities of Gilroy and Morgan Hill, CA which is also known as Coyote Valley (Figure 1). The Reserve is located $18 \mathrm{~km}$ east of Gilroy, CA in southern Santa Clara County, and was purchased by the California Department of Fish and Wildlife (CDFW) in 2001 to protect and enhance wildlife habitat and to provide a site for a youth outdoor education. The Reserve supports 2,347 hectares of oak woodlands, grasslands, mixed chaparral and riparian environments. As an ecological reserve, this is an ideal area for studying wildlife in a relatively undisturbed natural habitat near urban and agricultural areas in California. The study area also included agricultural fields and residential development in the cities of Morgan Hill and Gilroy. The Cañada de los Osos Ecological Reserve is located $18 \mathrm{~km}$ away from the nearest agricultural land use type used in this study, and $21 \mathrm{~km}$ away from the nearest developed land use type used in this study. Individual home ranges for the carnivore species in this research varied from $2 \mathrm{~km}$ for the 
smaller mesopredators to $595 \mathrm{~km}$ for the larger apex predators (Defenders of Wildlife, 2017) and all carnivore species that were targeted for this study have been known to occur in the central coast of California (Wang et al., 2015). Population growth in Gilroy, CA has dramatically increased within the past few decades. The population of Gilroy grew $25.3 \%$ from 2000 to 2014 with a population of 52,533 in 2014. While Morgan Hill had a population increase of $24 \%$ since the year 2000 , and has a population of 42,068 according to the 2014 U.S. Census of Population and Housing. This study area has been identified as an important region for wildlife movement between the Santa Cruz Mountains and the Diablo Range (Coyote Valley Linkage Assessment Study, 2016). According to the Coyote Valley Linkage Assessment Study (2016) the area "provides food and water resources, breeding and natal den habitat, and juvenile dispersal habitat, however, there is not much known on wildlife movement across the valley floor and what habitat wildlife species are using”. A major highway, Highway 101, intersects the study area and is a barrier to movement for wildlife species and a source of mortality due to high rates of animal-vehicle collisions (Urban Carnivores, 2010). Highway 101 separates the developed land use types to the west of the highway, from the agricultural and Reserve land use types to the east of the highway (Figure 1). This fragmentation can lead to reduced genetic flow and diversity between populations, which reduces the health of wildlife populations and ability to withstand disease (Road Ecology, 2003). 


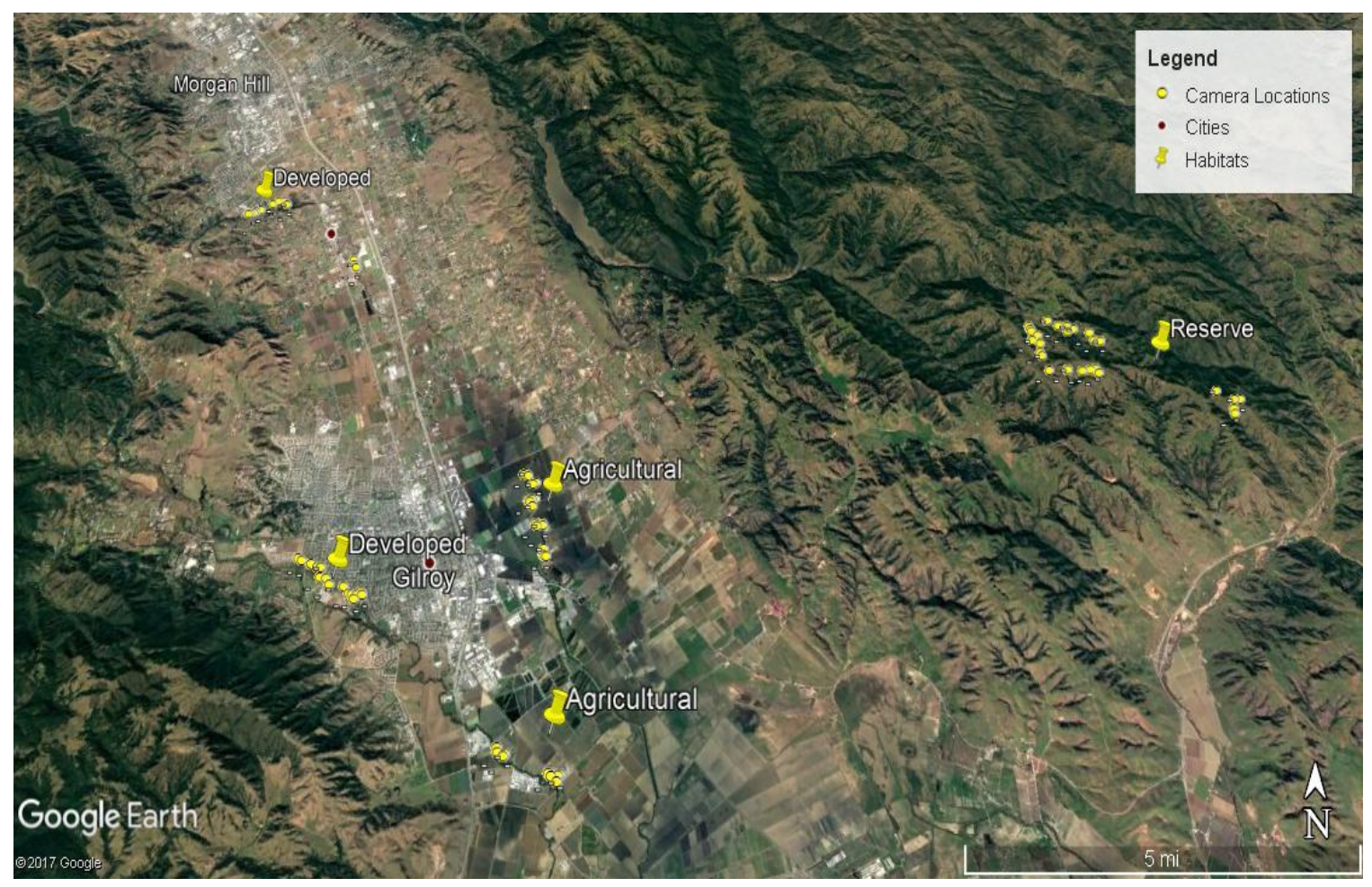

Figure 1. Regional map showing the study area. with camera locations throughout the region. Satellite imagery from Google Earth, 2017.

The sites within the Reserve used for this study included Old Corral Pond on Rocci's Road, Rocci's Road, Spring Valley Road, Wilson Ranch Road, Big Springs Road, and Elephant Ridge Road. The study sites within the urban areas included Easy Street in Morgan Hill, Llagas Ave in San Martin and Uvas Park Drive in Gilroy. The agricultural sites used for this study included Holsclaw Road and Bolsa Road in Gilroy. Habitat types were classified by extracting percent land cover of habitat features by use of GIS through the California Department of Fish and Wildlife Biogeographic and Information and Observation System's (CDFW BIOS, 2015) website, (Kelly \& Holub, 2008). Habitat types were generalized using the National Land Cover Database, 2011 (NLCD) into three types of land use: developed, agricultural, reserve (Riley et al., 2003). Developed 
habitats included medium and high intensity development. Medium intensity development is defined as "areas with a mixture of constructed materials and vegetation. Impervious surfaces account for $50 \%$ to $79 \%$ of the total cover. These areas most commonly included single-family housing units. High intensity development is defined as "highly developed areas where people reside or work in high numbers. Examples included apartment complexes, row houses and commercial/industrial buildings, where impervious surfaces account for $80 \%$ to $100 \%$ of the total cover" (NLCD, 2011) (Figure 2).

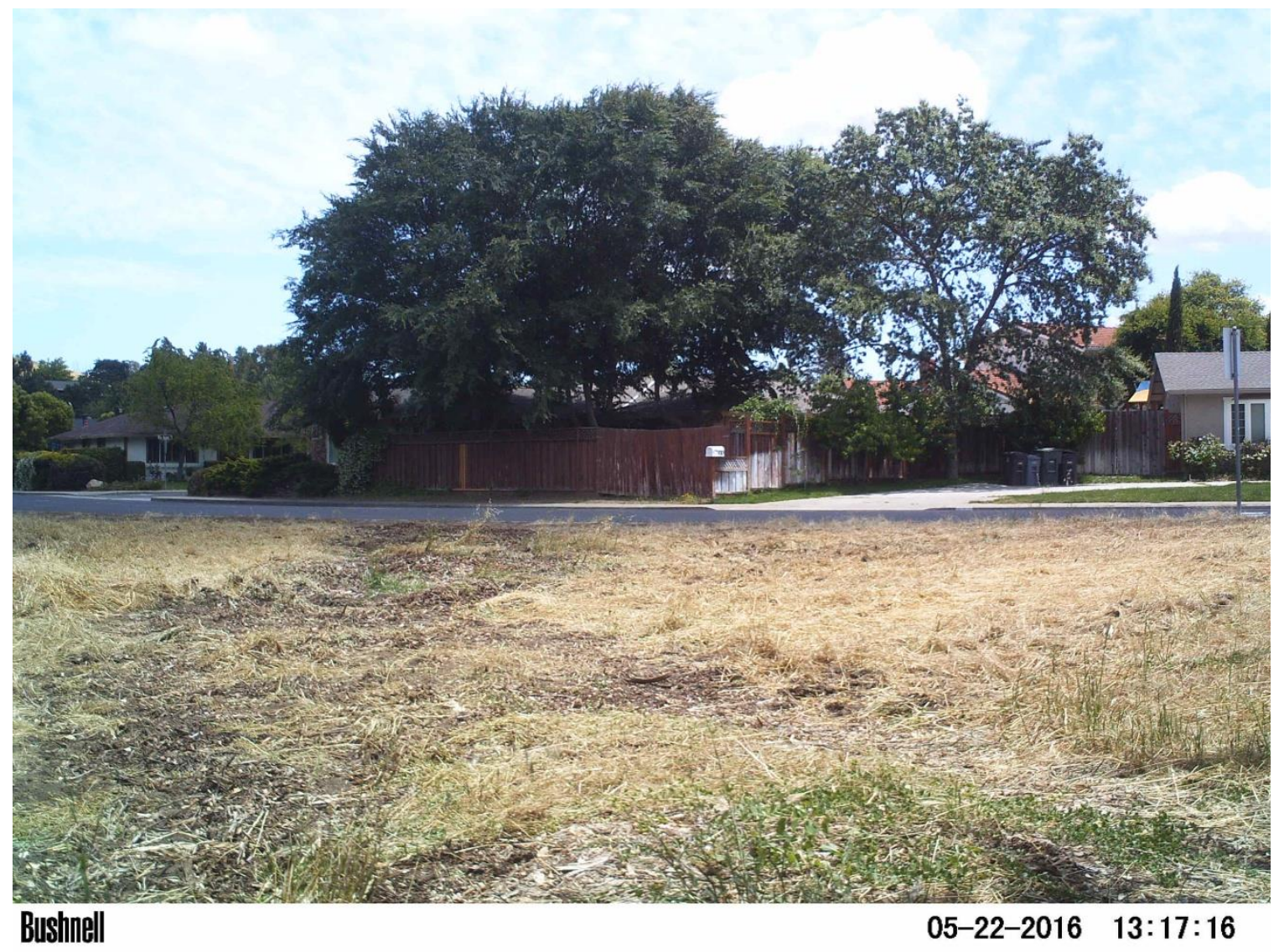

Figure 2. Camera station located in the developed land use in Morgan Hill, CA. 
Agricultural habitats used in this study included pasture/hay fields as well as cultivated crops. Pasture/hay fields included areas of grasses, legumes, or grass-legume mixtures planted for livestock grazing or for the production of seed or hay crops, typically on a perennial cycle. Cultivated crops are "areas used for the production of annual crops, such as corn, soybeans, vegetables, tobacco, and cotton, and also perennial woody crops such as orchards and vineyards. This class also included all land being actively tilled" (NLCD, 2011) (Figure 3).

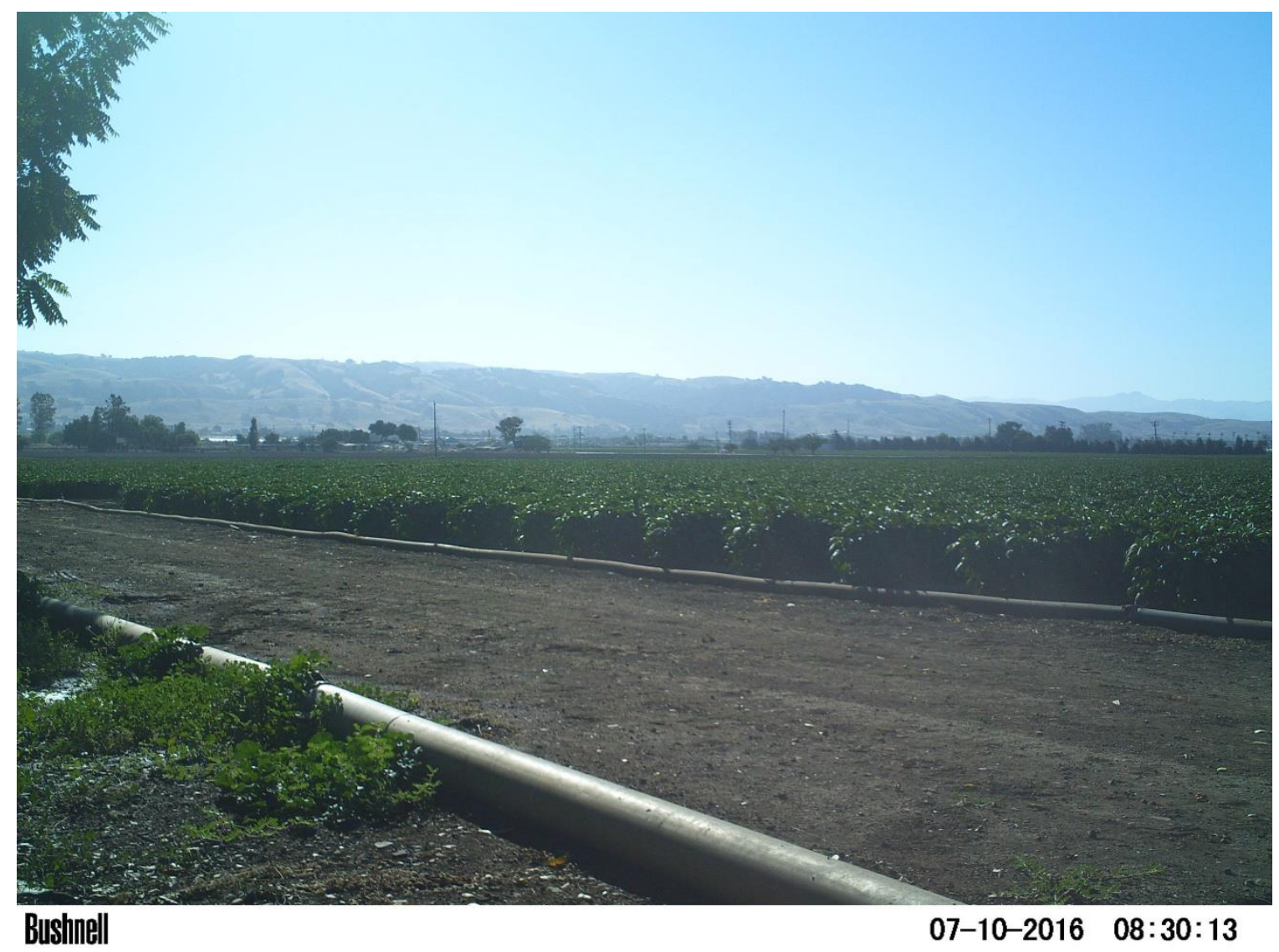

Figure 3. Camera station located in the agricultural land use in Gilroy, CA. 
Finally, the protected Reserve was defined as deciduous, evergreen and woodland forests. Deciduous forest included; "areas dominated by trees generally greater than 5 meters tall, and greater than $20 \%$ of total vegetation cover. More than $75 \%$ of the tree species shed foliage simultaneously in response to seasonal change". Evergreen forest included; "areas dominated by trees generally greater than 5 meters tall, and greater than $20 \%$ of total vegetation cover. More than $75 \%$ of the tree species maintain their leaves all year and the canopy is never without green foliage". Mixed forest included; "areas dominated by trees generally greater than 5 meters tall, and greater than $20 \%$ of total vegetation cover, where neither deciduous nor evergreen species are greater than $75 \%$ of total tree cover" (NLCD, 2011) (Figure 4). 


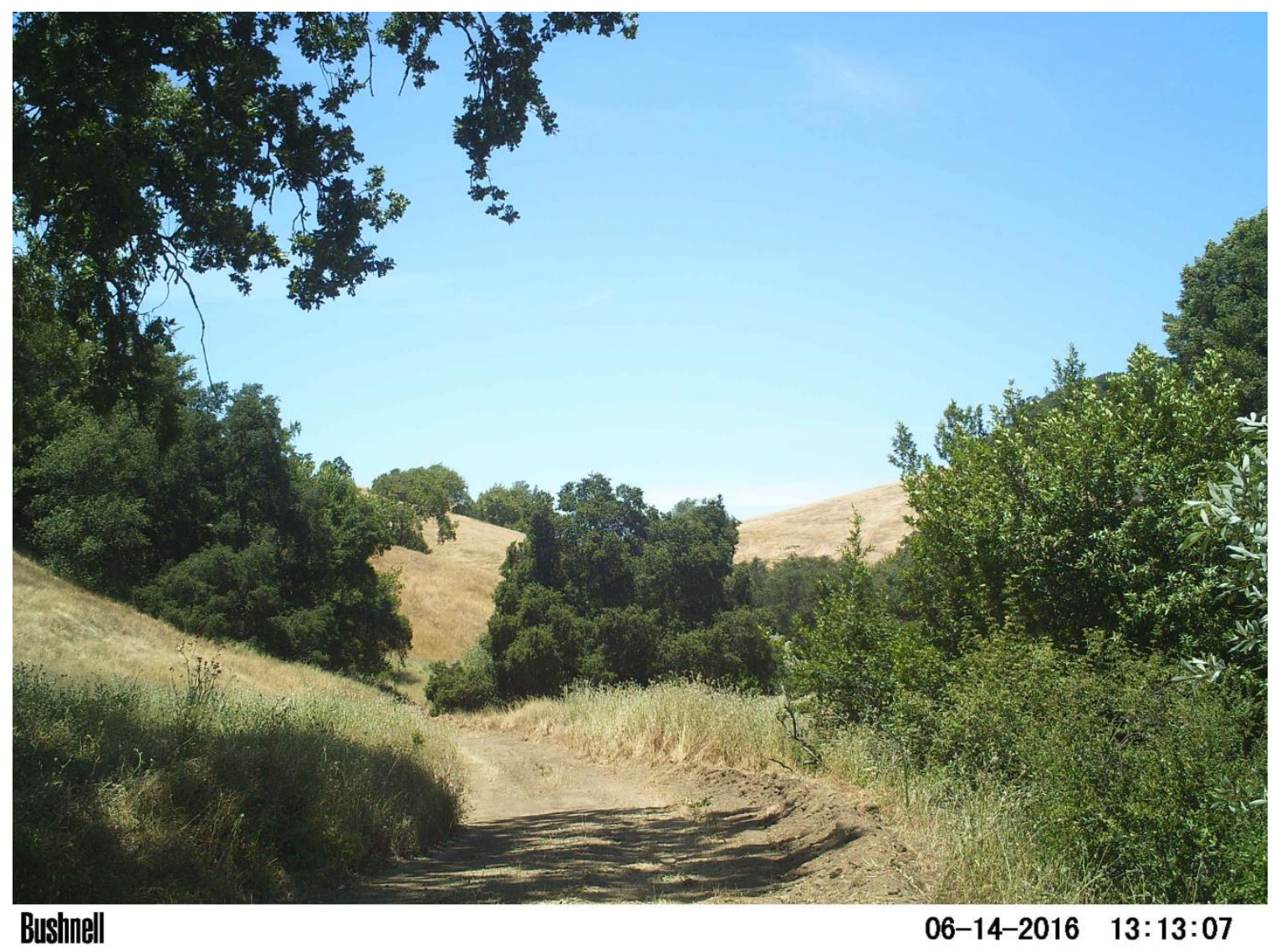

Figure 4. Camera station in the Canada De Los Osos Ecological Reserve, CA, the "Reserve" land use type.

\section{Study Design}

I collected data using remote camera traps, on terrestrial mammalian carnivore species in the Cañada de los Osos Ecological Reserve, local agricultural lands and developed cities. Carnivore species recorded by similar studies in the region include: mountain lions (Puma concolor), raccoons (Procyon lotor), striped skunks (Mephitis mephitis), coyotes (Canis latrans), bobcats (Lynx rufus) grey foxes (Urocyon cinereoargenteus) as well as one omnivore species, Virginia opossums (Didelphis virginiana) (Crooks, 2002; Kasey, 2008; Wang et al., 2015). 
Between April 2016 and September 2016, I placed transects of remote camera traps (Bushnell Trophy Cameras) in three distinct land use types (protected Reserve, agricultural, and developed) at various locations throughout the study site (Figure 1). In each land use type (Reserve, agriculture and developed) there was one transect consisting of five cameras at all times for a total of 15 cameras running consecutively 24 hours a day. Cameras in each land use type were moved to a new transect every three weeks. There were six distinct transects in each land use type over the course of the study, for a total of 90 different camera stations with 30 different stations in each land use. Batteries and SD cards were removed and replaced at each location every time a new transect was set up. Each transect location contained a riparian habitat, a road directly parallel to the riparian habitat, and a land use component, which consisted of either a protected woodland, agricultural, or developed area. Along each transect, two cameras were placed in the riparian habitats, one camera was placed adjacent to the road, and at least two cameras were placed in the designated land use areas (woodland Reserve, developed and agricultural). Each transect location was placed within one of the designated land use types using the BIOS Land Cover Map. Thus, each individual camera location was located within the land use type being examined. Specific transect locations were restricted to the necessary land use types (BIOS Land Cover Map), the riparian component, which included either a stream or river adjacent to each transect and a road or game trail parallel to the river or stream (Figure 5). This stratified randomize camera selection and the three week transect timeframe was done in order to maximize trapping success of elusive carnivore species (Gompper et al., 2006 \& Wang et al., 2015). 


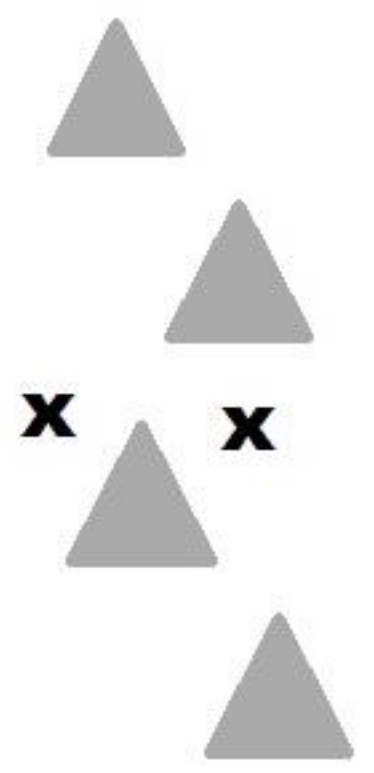

Land Use

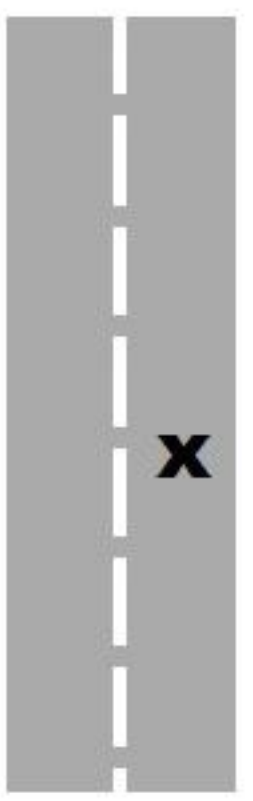

Road

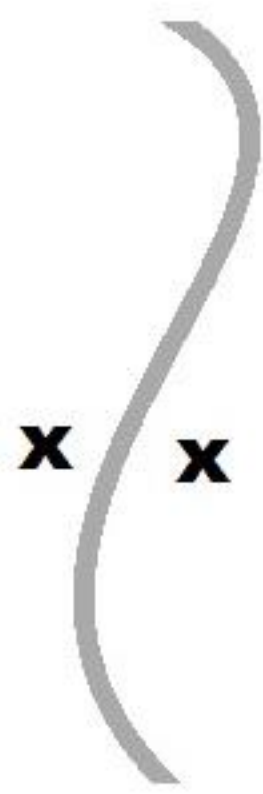

Riparian

Figure 5. Transect design of all three land use types with camera set up. ( $\mathrm{X}=$ camera placement).

Transects were spaced at least $1 \mathrm{~km}$ apart from one another within each land use type, in an effort to prevent cameras from double counting the same individual animals.

Bushnell Trophy Cameras were mounted on a tree or post approximately 1-2 meters above the ground (Wang et al., 2015) (Figure 6) (Figure 7). No lures were used to draw in animals. Cameras were set to run 24 hours a day and were triggered by any movement or heat that happened to move in front of a camera. Cameras were programmed to take two photographs when triggered with a one-minute delay between successive image sets (Wang et al., 2015). If an individual animal was detected more than once within an hour at the same camera location, the animal was only recorded once within that hour timeframe to avoid double counting (Wang et al., 2015). 
Each camera recorded the date, time, location of the photograph, and the number of individuals per photograph. These references allowed for analysis of patterns related to spatial and temporal characteristics, among others (Sanderson, 2002 \& Kacey, 2008). Occurrence in each photograph was assigned with a score of 1 for presence or 0 for absence for all photos (Ordeñana et al., 2010). Data was excluded from analysis when the field of view of the camera had been altered or obscured or when a camera malfunctioned. This occurred from human, animal or vegetation interference.

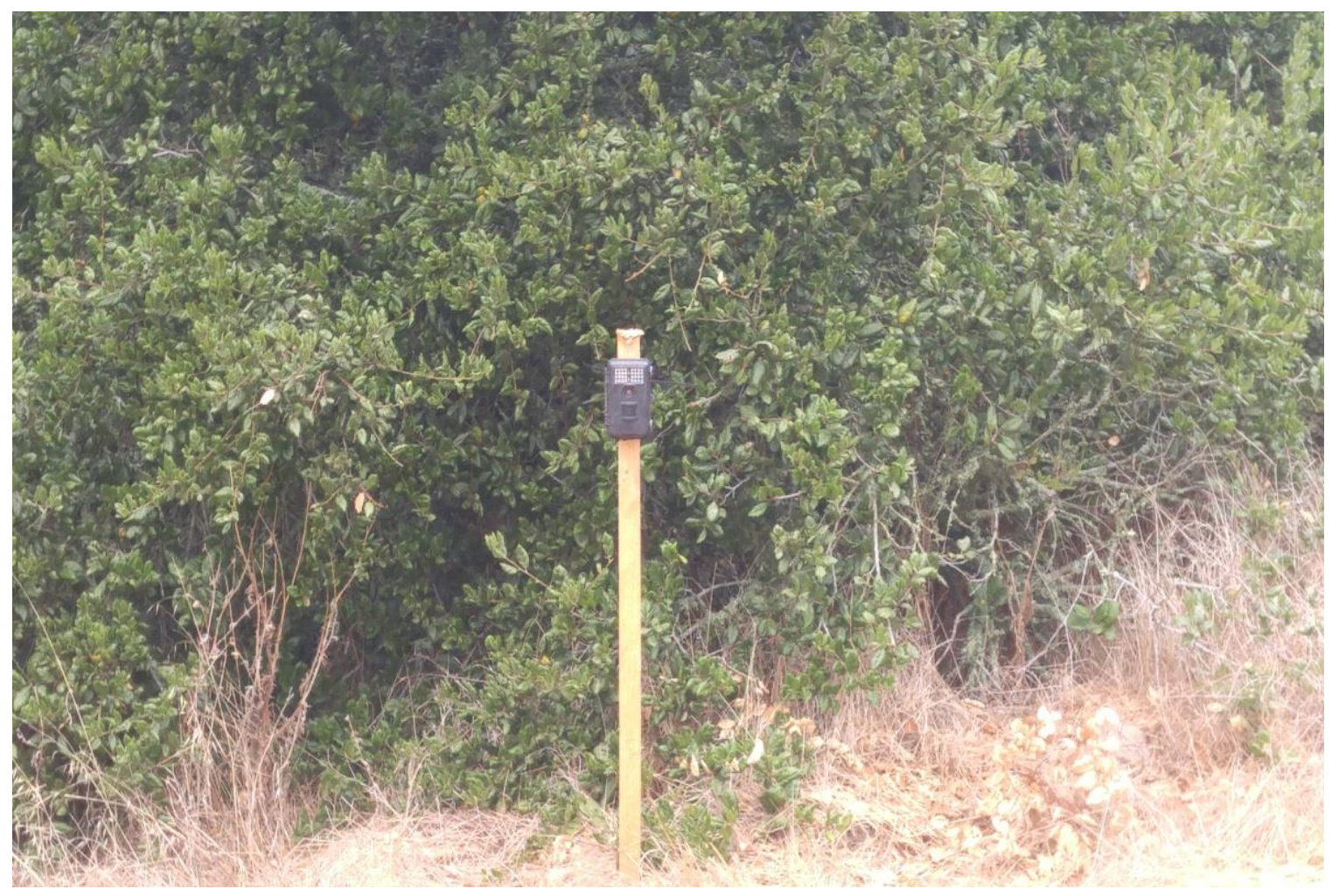

Figure 6. Bushnell Trophy Camera mounted on a post. 


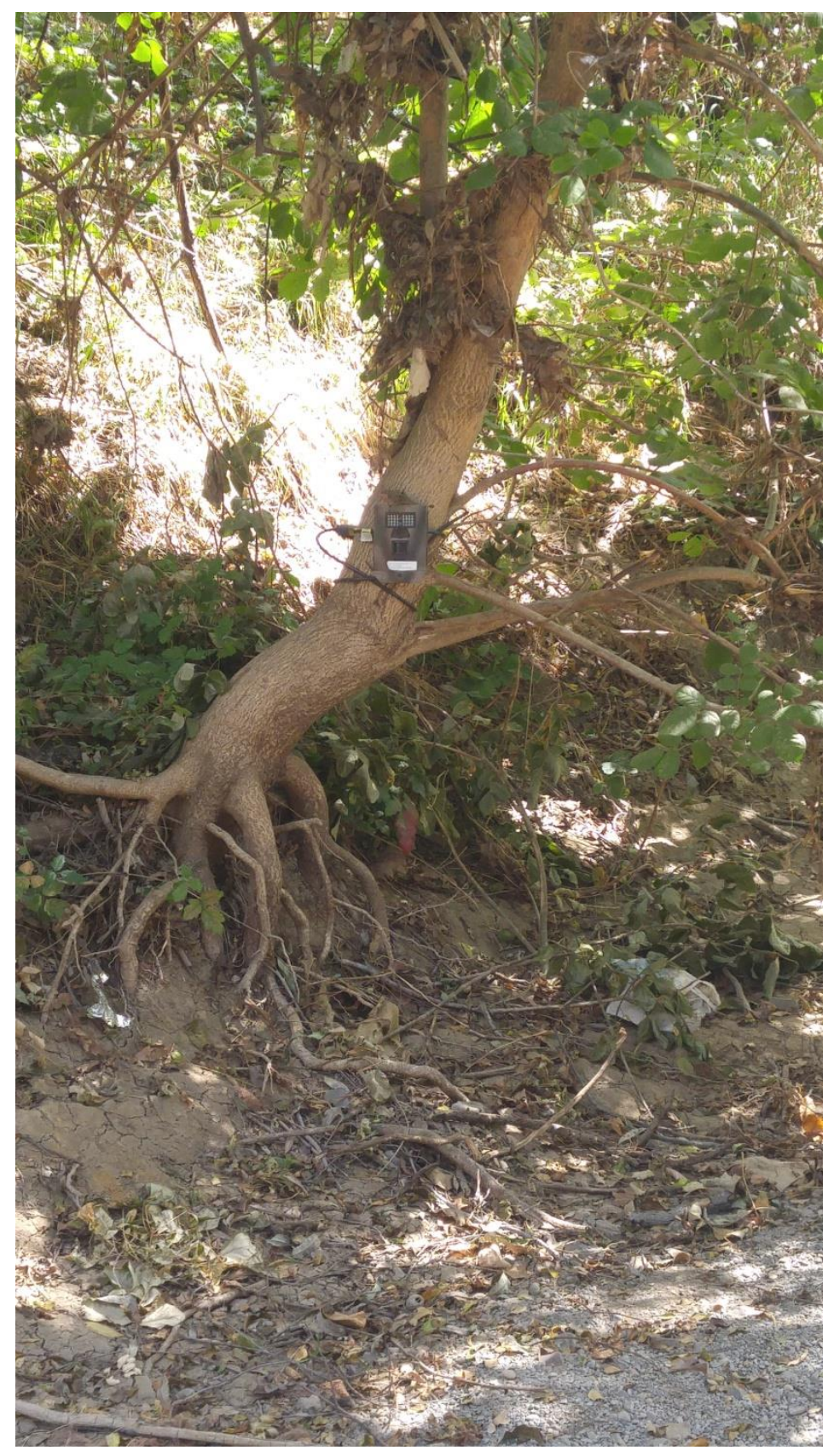

Figure 7. Bushnell Trophy Camera mounted on a tree.

\section{Data Analysis}

I used SYSTAT 13 for descriptive statistics to compare frequencies of species by land use type. This was accomplished after all camera trap photos were meticulously analyzed 
for presence of each species within each land use type. I ran Kruskal-Wallis tests to analyze whether carnivore species frequencies differed between the three land use types.

Descriptive statistics were also used to analyze activity times for each species. Each land use type had slightly varying camera time totals, so frequency of detection per 24 hour observation period was used to standardize frequencies. Activity times for each carnivore species was reported as the number of captures within each designated time segment, and within each land use type. There were four different time segments; each segment was designated with six hour blocks to represent the night, early morning, afternoon, and late afternoon.

To analyze the habitat preferences for each carnivore species, it was necessary to examine in greater depth the three land cover types that were outlined in the study. All camera trap locations were surveyed to determine habitat types at each camera site using the National Land Cover Database, 2011, which was found in the California Department of Fish and Wildlife's Biogeographic Information and Observation System (BIOS). There were thirteen total habitats identified using the BIOS GIS Land Cover Map which included orchard, pond, golf courses / urban parks, mixed riparian forest, valley oak woodland, willow riparian forest and scrub oak, grain, row-crop, hay and pasture, fallowed, rural residential, California annual grassland, agriculture developed, coast live oak forest and woodland, urban - suburban, and rural residential. Numbers of detection for each species in each land cover type were analyzed as a percentage of the total number of detections for each species. 
I also used the occupancy package "R" PRESENCE to explore how apex predators and land use conversion influenced mesopredator occupancy and detection rate. This "R" PRESENCE package utilized a maximum-likelihood estimation modeling approach to compare all models (Wang et al., 2015). Occupancy models improve upon traditional methods of examining spatial patterns of species occurrence by providing unbiased estimates of species occupancy and explicitly accounting for imperfect detection (Wang et al., 2015). Occupancy modeling accounts for the possibility that a species may be present at a site but not detected during a survey. Given this possibility detection can be the same as presence, but non-detection does not necessarily mean absence.

I modeled interactions between three different land use types and six wild carnivore species, two domestic carnivore species and one wild omnivore species with top models (DAIC < 2) summarized in Appendix A. The data for this study was parceled into sets of 20-day intervals, with 86 different camera sites/locations that were usable. All values within the matrix are 0 (nothing captured), 1 (species seen) and NA (camera offline). Raccoon data was used as a baseline for the occupancy modeling for the occupancy analysis. Because of the small sample size, using two species occupancy models was not possible, so naïve presence was used as a covariate instead. Coyote, mountain lion, and land use were also used as covariates for occupancy modeling. Coyote data was run separately because coyote was used as a covariate in the other models. In the end, 32 different models were run successfully. When delta AIC was less than or equal to 2, convergence of at least 3 significant digits, and when there were no variance covariance warnings, then the model could be reliably used for analysis. Using deer as a variable 
had issues with convergence so models related to this species could not be used. To determine detectability, I used camera placement and land use type as covariates. Once a reliable model was identified, pair-wise comparisons were used to determine if land use conversion affected the occupancy of mesopredator species, and if the presence of top predators affected the occupancy of mesopredator species. The "R" software was also used to analyze the activity times of each species in each land use type by summarizing the capture rates for each species in different time resolutions. 


\section{Results}

\section{Species and Land Use Types}

During the course of the study there were 1,877 images of wildlife species that were acceptable to use for data in this study. Six native carnivore species were detected throughout the study: mountain lion (Puma concolor), raccoons (Procyon lotor), striped skunks (Mephitis mephitis), coyotes (Canis latrans), bobcats (Lynx rufus), and grey foxes (Urocyon cinereoargenteus), as well as one omnivore species: Virginia opossum (Didelphis virginiana), and two non-native carnivore species: domestic dog (Canis lupus familiaris), domestic cat (Felis catus). There were also six different mammalian prey species detected including: black-tailed jackrabbit (Lepus californicus), California ground squirrel (Otospermophilus beecheyi), back-tailed deer (Odocoileus hemionus), wild boar (Sus scrofa), brush rabbit (Sylvilagus bachmani). There were 17 photos classified as “unknown”, when a species could not be positively identified.

Mountain lions were found only in the Reserve and at very low frequencies $(\bar{x}=0.021$ detections/24 hour observation period, $\mathrm{SE}=0.008$ ).

There was a significant difference between agriculture and the Reserve $(\mathrm{H}=25.072$, $\mathrm{t}=6.416, \mathrm{df}=2, \mathrm{P}=0.000)$ and developed and Reserve $(\mathrm{H}=25.072, \mathrm{t}=7.410, \mathrm{df}=2, \mathrm{P}=0.000)$ for coyote frequency, but not between agricultural and developed land uses $(\mathrm{H}=25.072$, $\mathrm{t}=-2.094, \mathrm{df}=2, \mathrm{P}=0.300$ ) for coyote frequency. There was a significant difference between agriculture and Reserve $(\mathrm{H}=11.743, \mathrm{t}=5.624, \mathrm{df}=2, \mathrm{P}=0.000)$ and developed and Reserve $(\mathrm{H}=11.743, \mathrm{t}=3.574, \mathrm{df}=2, \mathrm{P}=0.031)$ for bobcat frequency. The frequency of 
bobcat detections did not differ between agricultural and developed land uses $(\mathrm{H}=11.743$, $\mathrm{t}=2.276, \mathrm{df}=2, \mathrm{P}=0.241)$ (Figure 8 ).

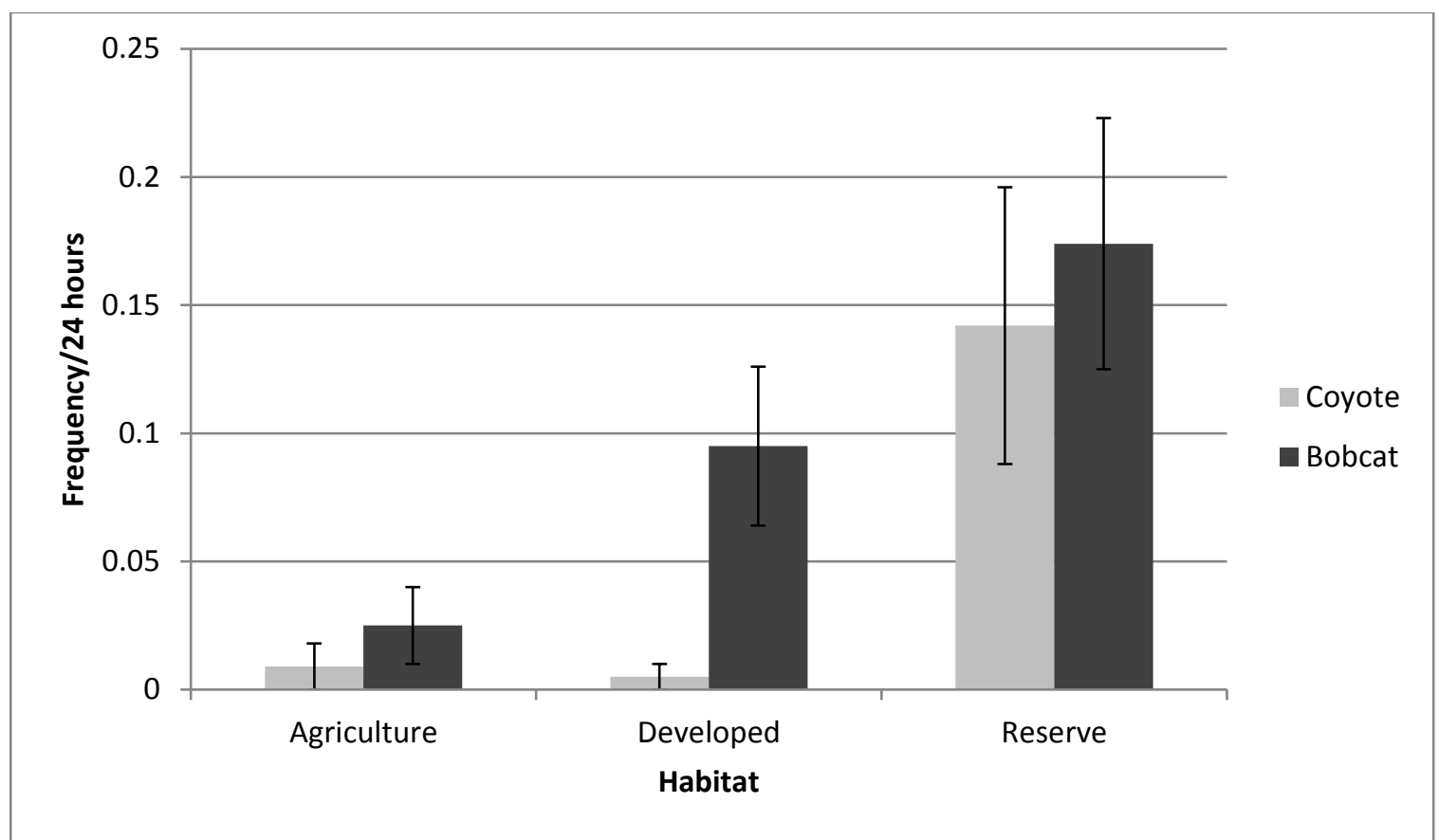

Figure 8: Frequency/24 hour period of coyotes and bobcats within each land use type.

Grey fox were found only in agriculture and developed land use types and the frequencies of detection/24 hour observation period did not differ between these land use types $(\mathrm{H}=4.643, \mathrm{t}=-2.499, \mathrm{df}=2, \mathrm{P}=0.181)$ (Figure 9). 


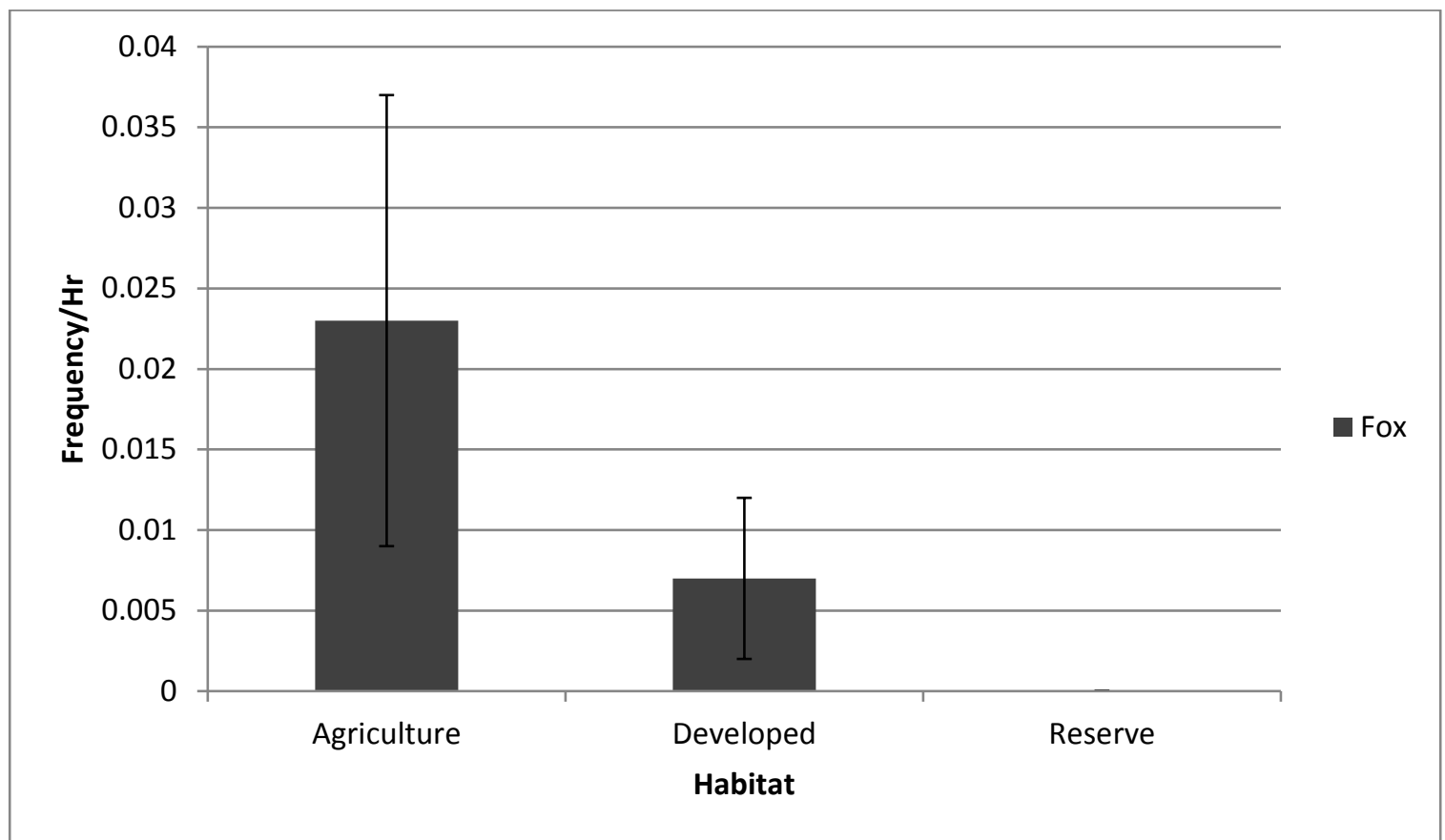

Figure 9: Frequency/24 hour period of grey fox within each land use type.

The frequency of skunk detection did not differ between agriculture and developed $(H=2.316, t=0.941, d f=2, P=0.784)$, agriculture and Reserve $(H=2.316, t=2.812, d f=2$, $\mathrm{P}=0.115)$ or developed and Reserve $(\mathrm{H}=2.316, \mathrm{t}=1.557, \mathrm{df}=2, \mathrm{P}=0.513)$. The frequency of opossum detections did not differ between developed and agricultural $(\mathrm{H}=9.677$, $\mathrm{t}=0.650, \mathrm{df}=2, \mathrm{P}=0.890$ ), nor was there a difference between agriculture and developed land uses $(\mathrm{H}=17.934, \mathrm{t}=-3.006, \mathrm{df}=2, \mathrm{P}=0.085)$. Neither opossums nor raccoons were detected in the Reserve (Figure 10). 


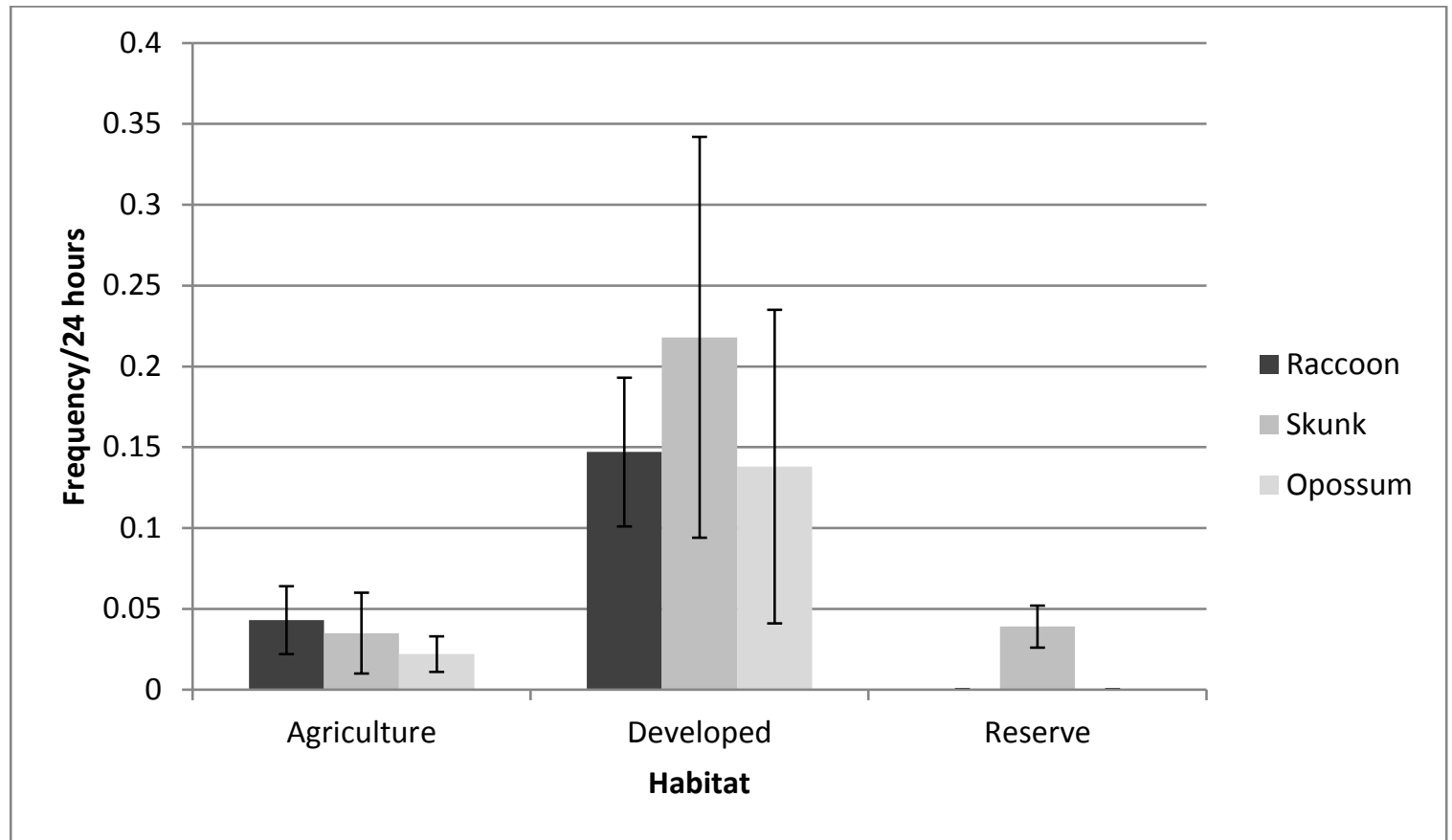

Figure 10: Frequency/24 hour period of raccoons, skunks, and opossums within each land use type.

Both domestic animals were significantly more common in developed versus agricultural land use types (dogs: $\mathrm{H}=23.333, \mathrm{t}=2.996, \mathrm{df}=2, \mathrm{P}=0.086$; cats: $\mathrm{H}=25.513$, $t=2.976, d f=2, P=0.089$ ). Neither dogs nor cats were detected in the Reserve (Figure 11). 


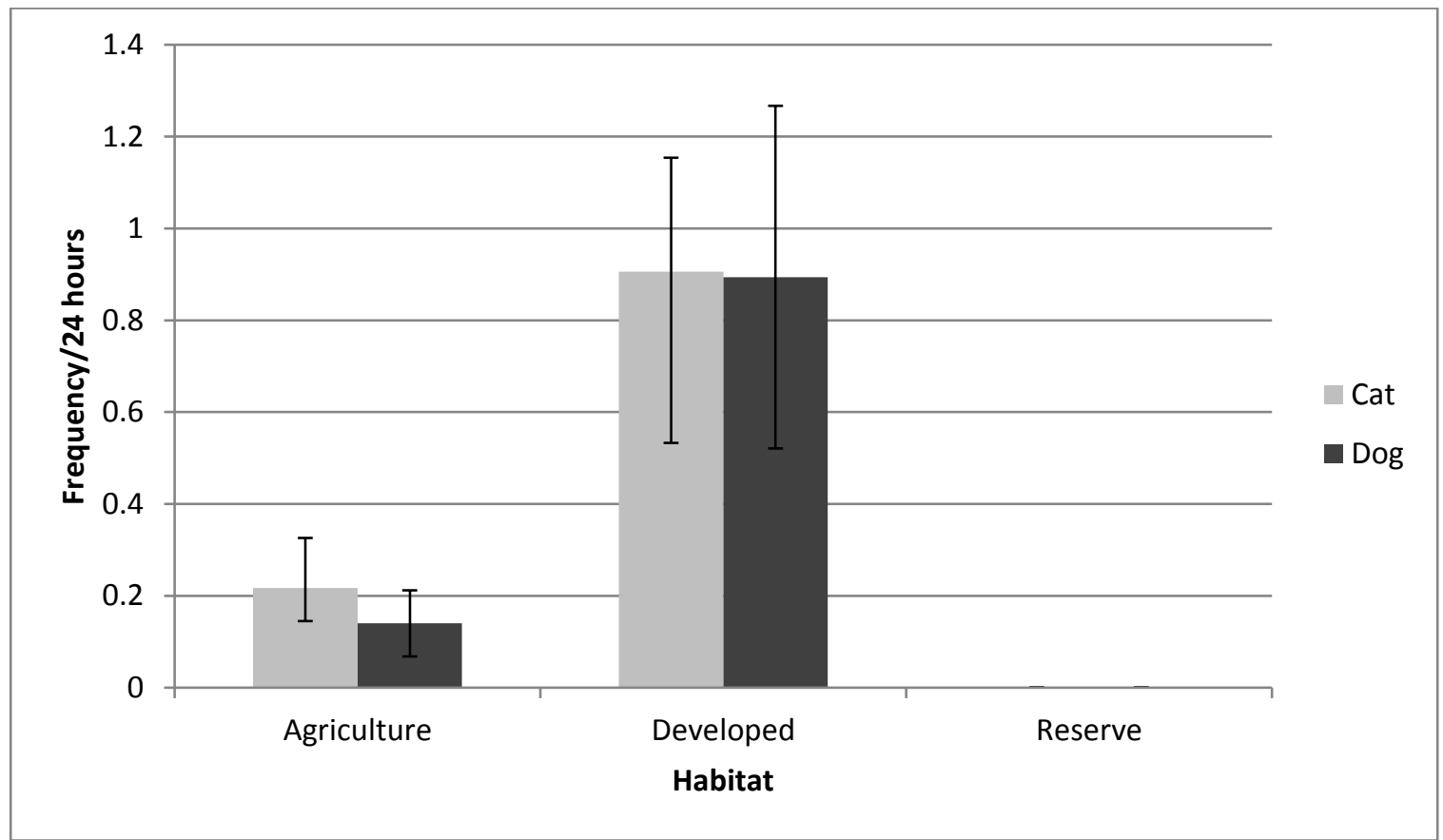

Figure 11: Frequency/24 hour period of cats and dogs within each land use type.

\section{Activity Times for Each Species}

Total camera hours per land used type were agriculture $=13,716$, developed $=11,528$ and Reserve $=13,395$. Total camera hours were slightly different because of camera malfunctions as well as some cameras being stolen in the field.

Mountain lions were detected most frequently in the late afternoon (18-24) and at night (0-6) in the Reserve. They were not detected in the developed and agricultural land use types (Figure 12). 


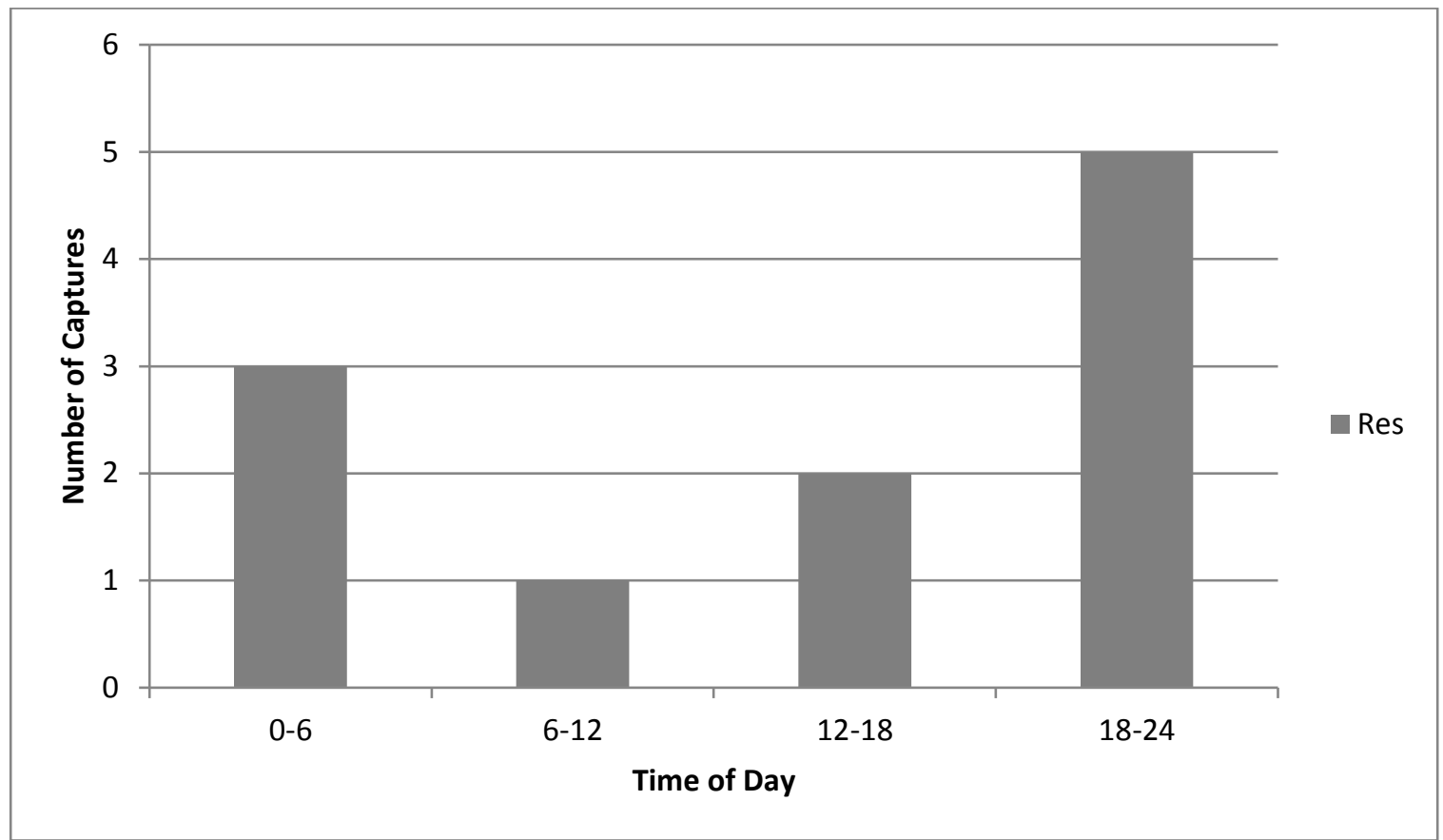

Figure 12: Mountain lion temporal activity patterns in the Reserve.

Coyotes were most active in the mornings (6-12) but were also active throughout the late afternoon (18-24) and at night (0-6). The majority of detections for coyote activity were found in the protected Reserve (Figure 13). 


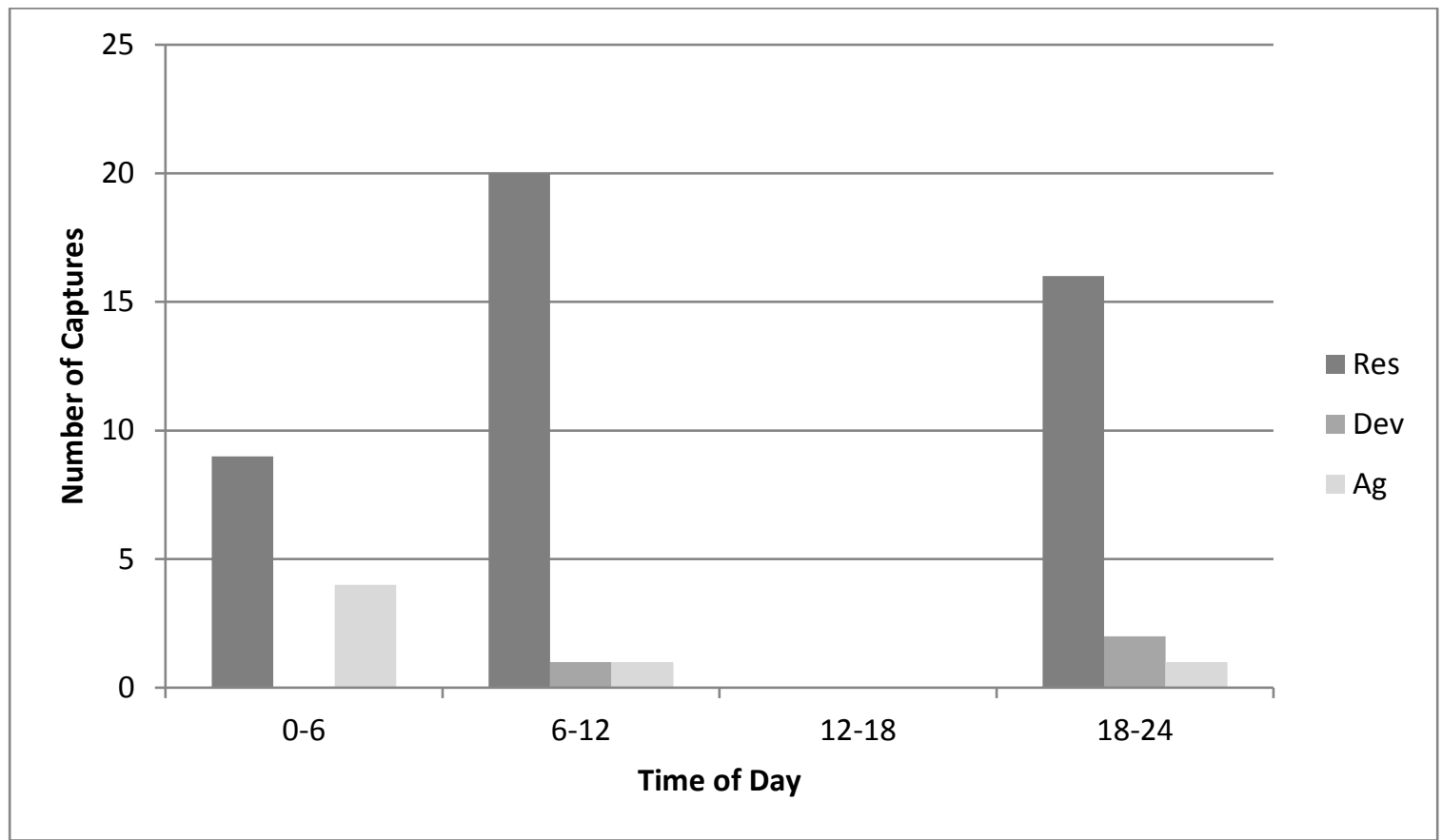

Figure 13: Coyote temporal activity patterns within each land use type.

Bobcats were most active in the late afternoon (18-24) and at night (0-6) in the Reserve. Bobcats did increase their activity times in the morning (6-12) and afternoon (12-18) in the developed land use types, compared to the Reserve (Figure 14). 


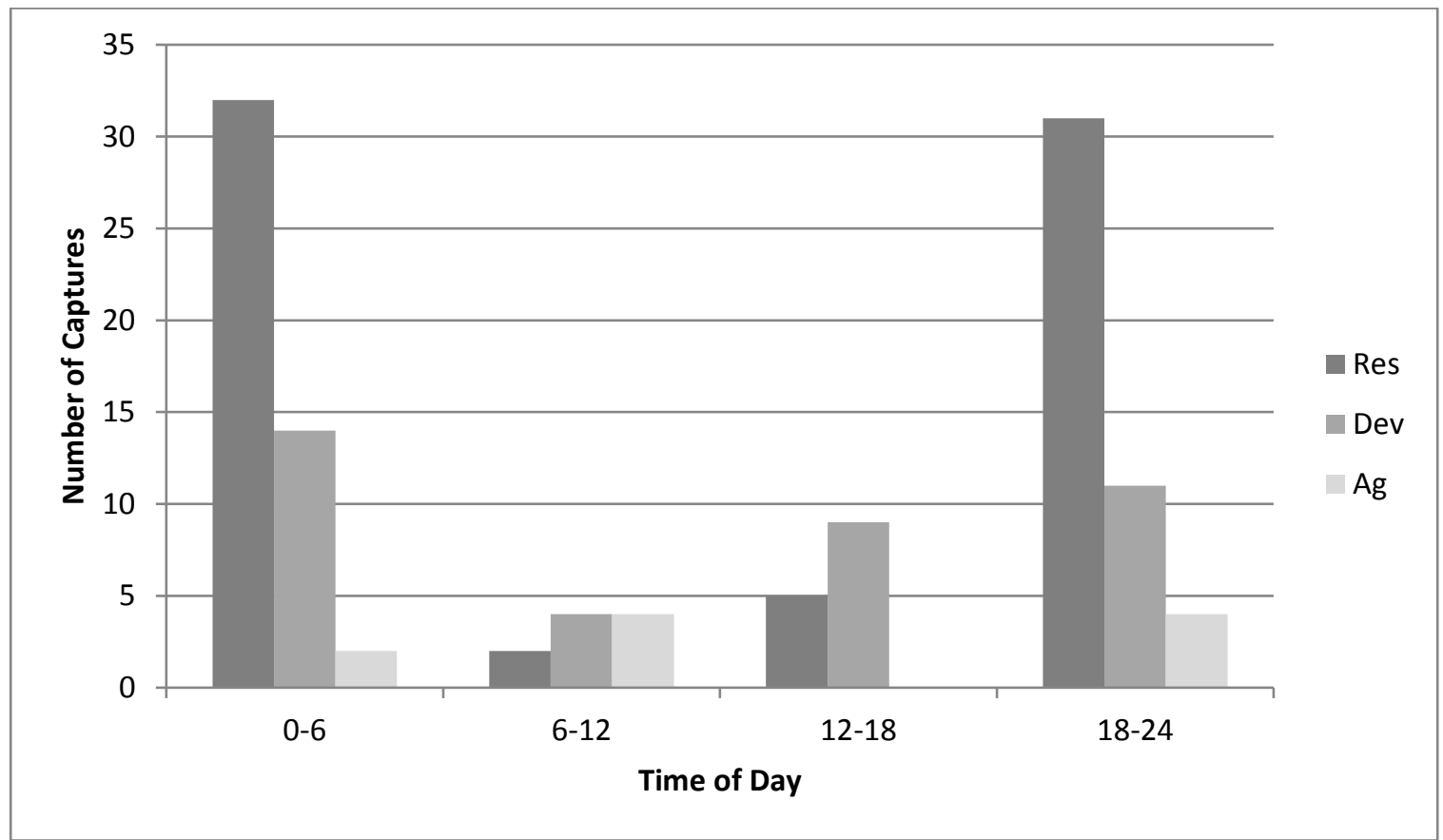

Figure 14: Bobcat temporal activity patterns within each land use type.

Grey foxes were active throughout the day, but were most active at night (0-6) in the agricultural land use type, and most active in the morning (6-12) in the developed land use type. Grey foxes were not detected in the Reserve (Figure 15). 


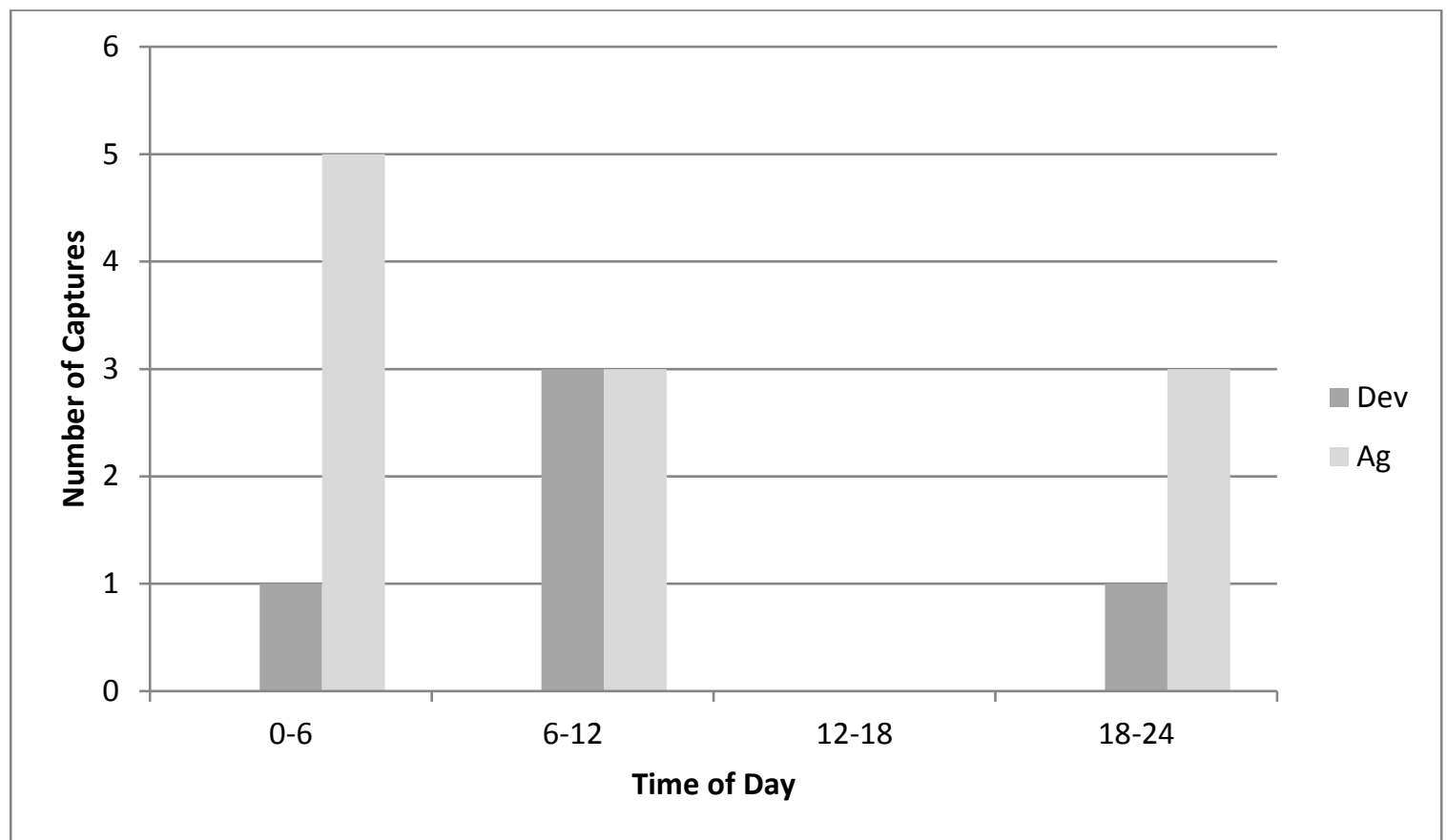

Figure 15: Grey fox temporal activity patterns within each land use type.

Skunks were found most often in the late afternoon (18-24) and at night (0-6) with most of captures detected in the developed land use type (Figure 16). 


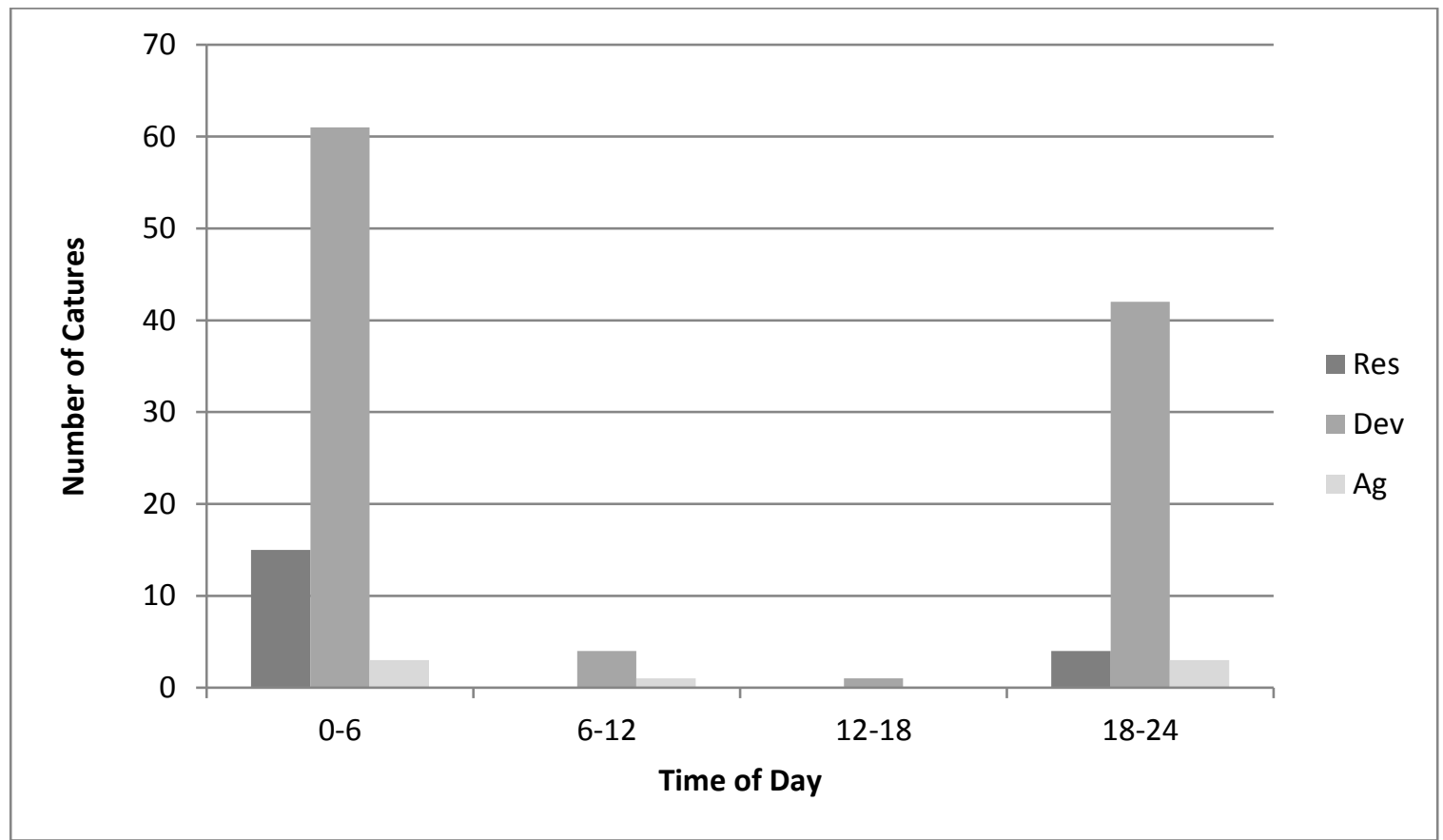

Figure 16: Skunk temporal activity patterns within each land use type.

Opossums were found most often in the late afternoon (18-24) and at night (0-6) with the vast majority of captures detected in the developed areas. Opossums were not detected in the Reserve (Figure 17). 


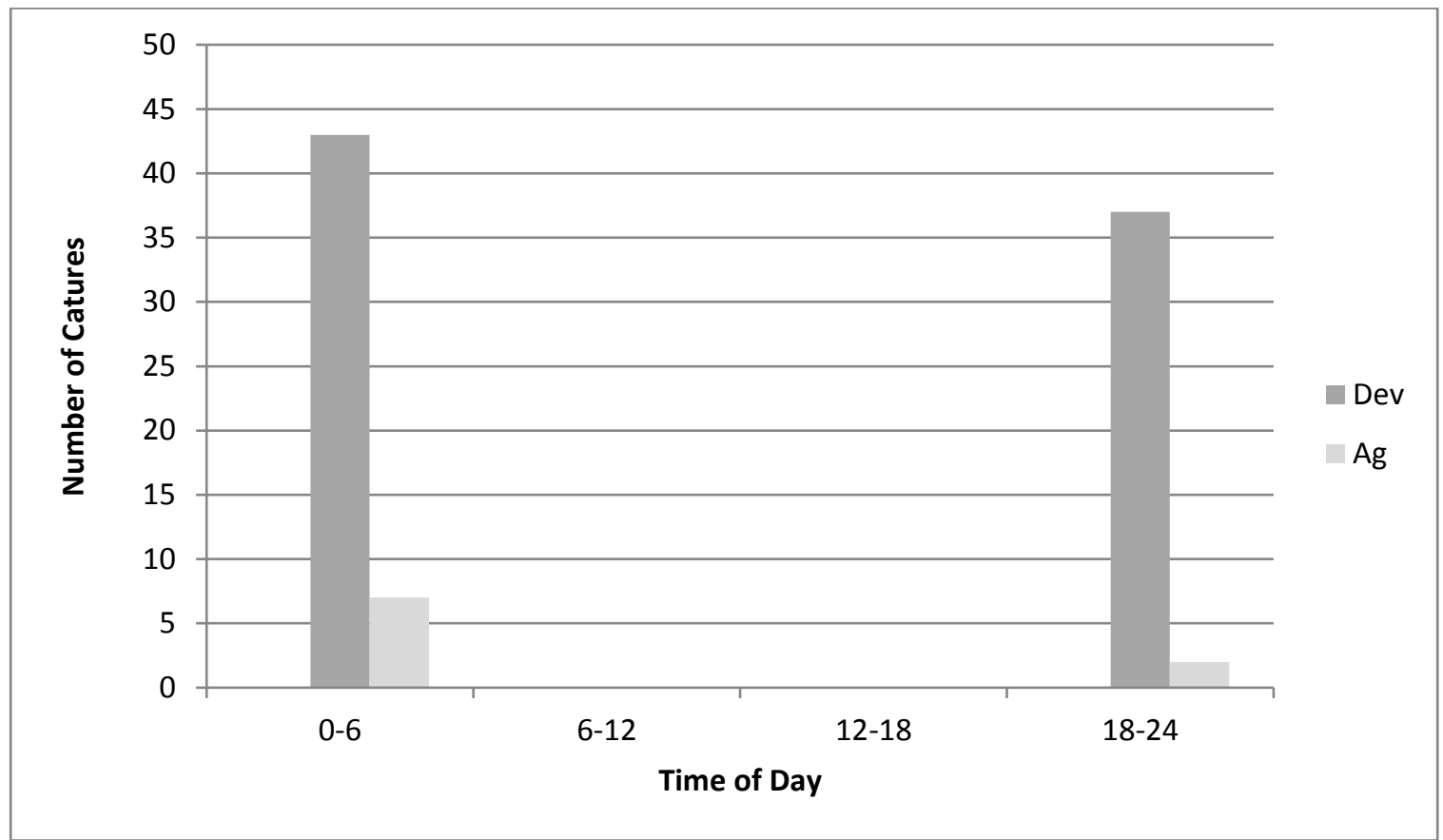

Figure 17: Opossum temporal activity patterns within each land use type.

Raccoons were found most often in the late afternoon (18-24) and at night (0-6) with the vast majority of captures detected in the developed land use type. Raccoons were not detected in the Reserve (Figure 18). 


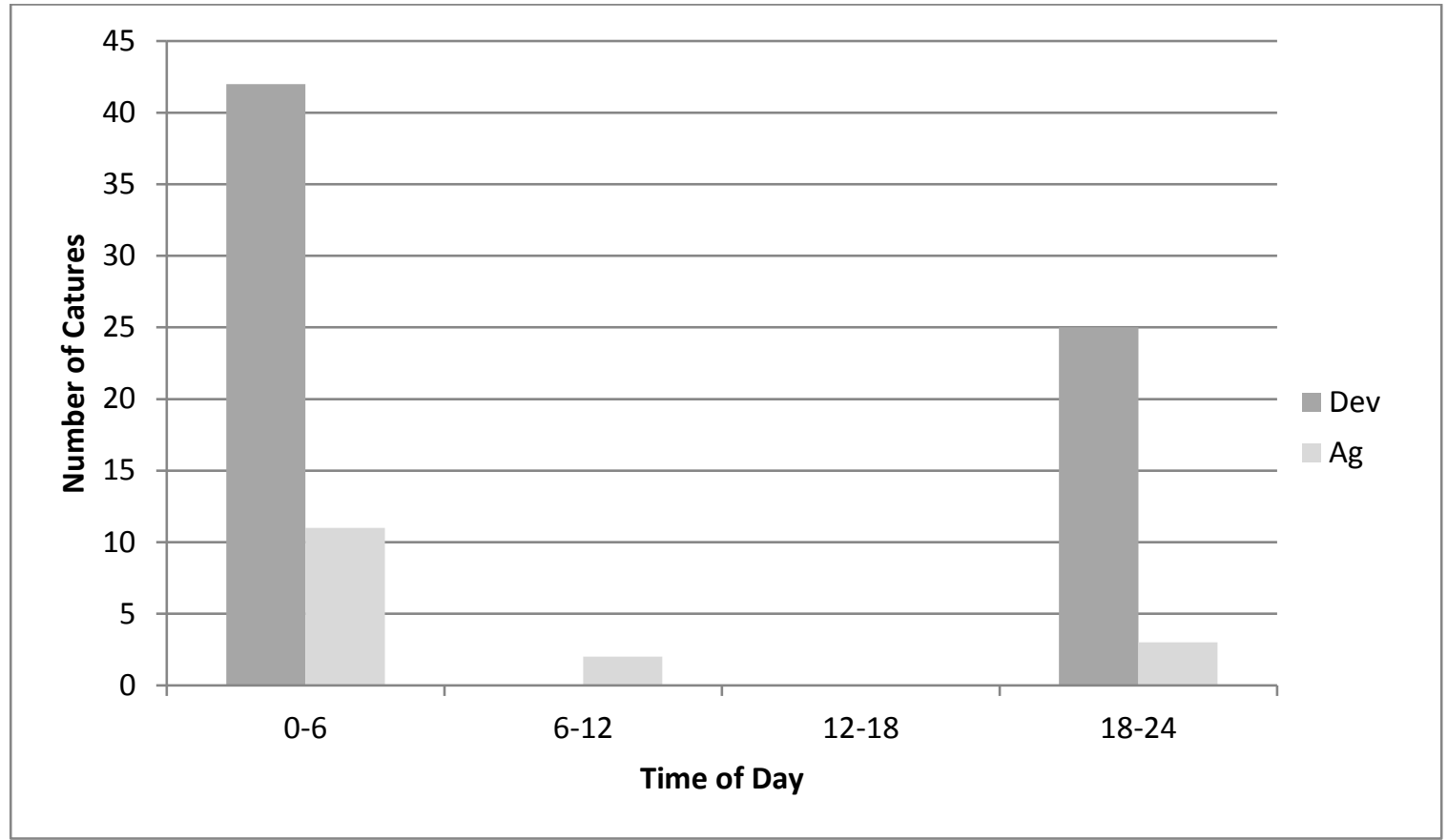

Figure 18: Raccoon temporal activity patterns within each land use type.

Cats were active throughout the course of the day, but were least active in the afternoon (12-18). Cats were not detected in the Reserve (Figure 19). 


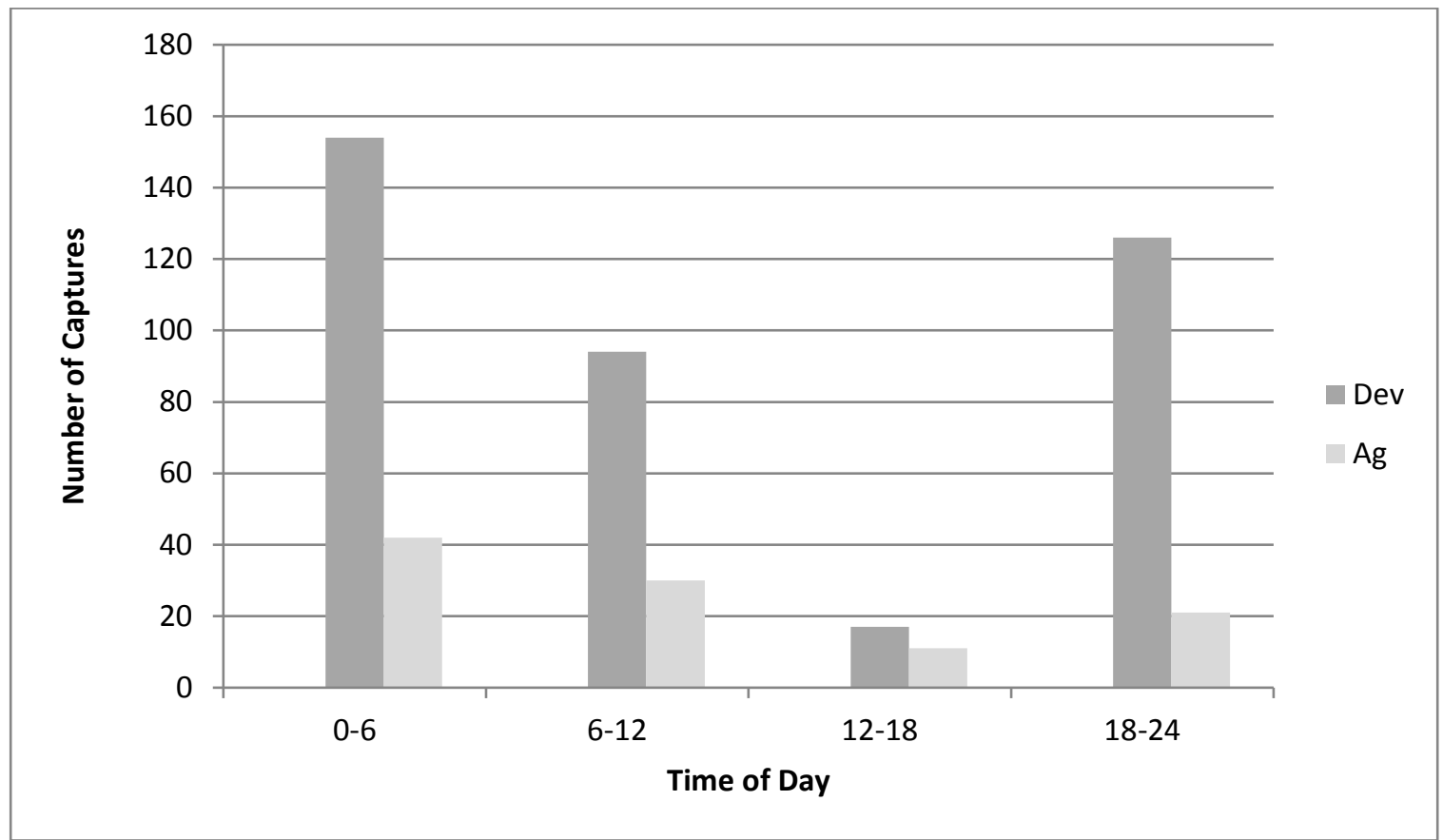

Figure 19: Cat temporal activity patterns within each land use type.

Dogs were active throughout the course of the day, but were least active at night (06). Dogs were not detected in the Reserve (Figure 20). 


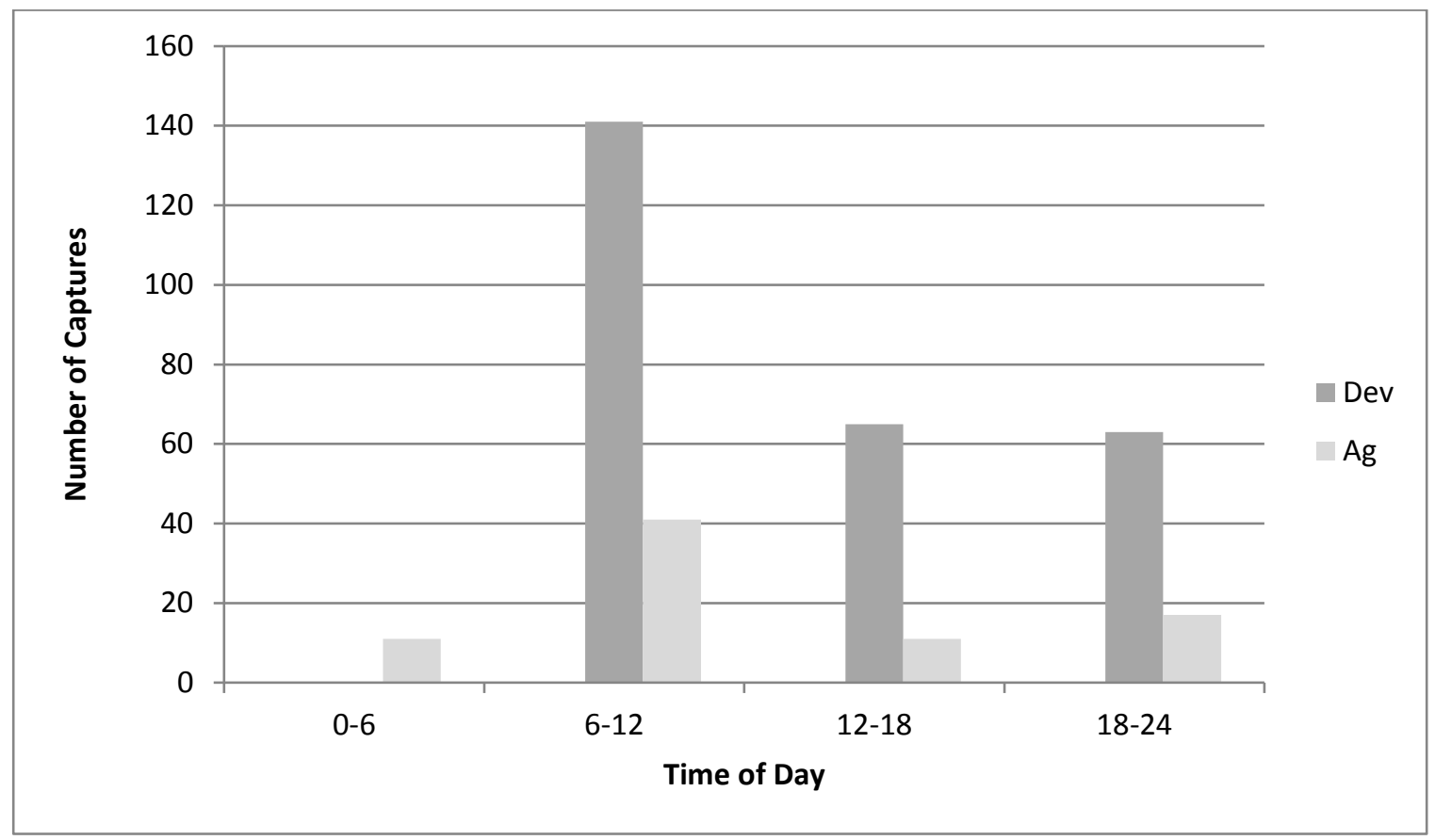

Figure 20: Dog temporal activity patterns within each land use type.

\section{Land Use Types' Affect on Mesopredator Species}

The results indicate land use type was a positive occupancy covariate for a few of the species in this study. In particular, bobcat occupancy was more likely in the Reserve $(b=$ $1.233, \mathrm{SE}=0.798)$ than in agriculture $(\mathrm{b}=-2.185, \mathrm{SE}=0.647)$ and bobcat occupancy was also more likely to be seen in the developed land use $(b=1.770, \mathrm{SE}=0.776)$ than in agriculture $(b=2.185, \mathrm{SE}=0.647)$. Results for this analysis also indicate that coyote occupancy was more likely in the Reserve $(b=1.770, \mathrm{SE}=0.892)$ than in agriculture $(b$ $=-2.511, \mathrm{SE}=0.737)$ and coyote occupancy was also more likely in developed $(\mathrm{b}=-$ $0.661, \mathrm{SE}=1.260)$ versus agriculture $(\mathrm{b}=-2.511, \mathrm{SE}=0.737)$.

\section{Mesopredators Response to the Presence of Top Predators}

I modeled interactions between top predators (mountain lion and coyote) and six subordinate carnivore species as well as one subordinate omnivore species with top 
models (DAIC < 2) summarized in Appendix A. There were several instances where top predator presence was positively correlated with the occupancy of subordinate species. However, there was one instance where the presence of mountain lions affected the occupancy of mesopredator species; mountain lion presence $(b=2.19, \mathrm{SE}=1.07)$ was positively correlated with coyote occupancy $(b=-2.511, \mathrm{SE}=0.737)$. Coyote presence $(b=1.484, \mathrm{SE}=0.606)$ was positively correlated with bobcat occupancy $(b=-0.998, \mathrm{SE}$ $=0.324)$. Coyote presence $(\mathrm{b}=1.484, \mathrm{SE}=0.606)$ was also positively correlated to cat occupancy $(b=-0.656, \mathrm{SE}=0.411)$.

\section{Preferred Habitat Preferences for Each Carnivore Species}

Table 1 shows the habitat types preferred by each carnivore species. Of the habitat types sampled in this study, the most common preferred was Mixed Riparian Forest, which was the preferred habitat for mountain lions, bobcats, coyotes, and raccoons. Grey fox was detected most often in Willow Riparian Forest and Scrub habitat types. Skunks and opossums were most often detected in the Urban-Suburban habitat types. Domestic dogs and cats were the most widely distributed species, frequenting a wide range of habitat types.

Table 1

Habitat Preferences of Each Species (shown as number of detections/habitat type).

\begin{tabular}{|c|c|c|c|c|c|c|c|c|c|}
\hline Habitat & $\begin{array}{c}\text { Mt. } \\
\text { Lion }\end{array}$ & $\begin{array}{c}\text { Bob } \\
\text { cat }\end{array}$ & $\begin{array}{c}\text { Coy } \\
\text { ote }\end{array}$ & Fox & $\begin{array}{c}\text { Rac } \\
\text { coon }\end{array}$ & $\begin{array}{c}\text { Sku } \\
\text { nk }\end{array}$ & $\begin{array}{c}\text { Opos } \\
\text { sum }\end{array}$ & Cat & Dog \\
\hline Orchard & 0 & 4 & 0 & 3 & 1 & 2 & 2 & 0 & 0 \\
\hline Pond & 0 & 1 & 2 & 0 & 0 & 0 & 0 & 0 & 0 \\
\hline $\begin{array}{c}\text { Golf } \\
\text { Courses/Urban } \\
\text { Parks }\end{array}$ & 0 & 0 & 0 & 0 & 2 & 7 & 2 & 24 & 32 \\
\hline
\end{tabular}




\begin{tabular}{|c|c|c|c|c|c|c|c|c|c|}
$\begin{array}{c}\text { Mixed Riparian } \\
\text { Forest }\end{array}$ & 8 & 80 & 27 & 1 & 56 & 46 & 20 & 222 & 133 \\
\hline $\begin{array}{c}\text { Valley Oak } \\
\text { Woodland }\end{array}$ & 0 & 6 & 2 & 0 & 0 & 0 & 0 & 0 & 0 \\
\hline $\begin{array}{c}\text { Willow Riparian } \\
\text { Forest and Scrub }\end{array}$ & 0 & 9 & 0 & 9 & 7 & 1 & 3 & 7 & 17 \\
\hline $\begin{array}{c}\text { Grain, Row-crop, } \\
\text { Hay and Pasture }\end{array}$ & 0 & 3 & 0 & 3 & 9 & 4 & 2 & 150 & 68 \\
\hline Rural Residential & 0 & 0 & 0 & 0 & 0 & 0 & 0 & 9 & 19 \\
\hline $\begin{array}{c}\text { California Annual } \\
\text { Grassland }\end{array}$ & 1 & 9 & 12 & 0 & 0 & 1 & 0 & 0 & 0 \\
\hline $\begin{array}{c}\text { Agriculture } \\
\text { Developed }\end{array}$ & 0 & 0 & 0 & 0 & 0 & 0 & 0 & 4 & 42 \\
\hline $\begin{array}{c}\text { Coast Live Oak } \\
\text { Forest/Woodland }\end{array}$ & 2 & 10 & 7 & 0 & 0 & 0 & 0 & 0 & 0 \\
\hline Urban - Suburban & 0 & 0 & 0 & 0 & 6 & 74 & 63 & 123 & 37 \\
\hline Rural Residential & 0 & 0 & 3 & 0 & 1 & 0 & 0 & 4 & 0 \\
\hline $\begin{array}{c}\text { Total Detections } \\
\text { per Species }\end{array}$ & 11 & 122 & 53 & 16 & 82 & 135 & 92 & 543 & 348 \\
\hline $\begin{array}{c}\text { Preferred Habitat } \\
\text { \% }\end{array}$ & $\begin{array}{c}\text { MR } \\
73 \%\end{array}$ & $\begin{array}{c}\text { MR } \\
66 \%\end{array}$ & $\begin{array}{c}\text { MR } \\
51 \%\end{array}$ & $\begin{array}{c}\text { WR } \\
56 \%\end{array}$ & $\begin{array}{c}\text { MR } \\
68 \%\end{array}$ & $\begin{array}{c}\text { UR } \\
55 \%\end{array}$ & $\begin{array}{c}\text { UR } \\
68 \%\end{array}$ & $\begin{array}{c}\text { MR } \\
40 \%\end{array}$ & $\begin{array}{c}\text { MR } \\
38 \%\end{array}$ \\
\hline
\end{tabular}

MR=Mixed Riparian Forest

$\mathrm{UR}=$ Urban - Suburban

$\mathrm{WR}=$ Willow Riparian Forest and Scrub

\section{All Terrestrial Mammalian Species Detected}

Table 2 shows that there were five terrestrial mammalian prey species detected in this study. The species detected include cottontail rabbit, Black-tailed deer, wild pig, California ground squirrel and black-tailed jackrabbit. The mammalian prey species that was detected most frequently in the developed and Reserve land use types was the Blacktailed deer, while the California ground squirrel was the mammalian prey species detected most frequently in the agricultural land use type. 
Table 2

Total Detections for all Mammalian Species Detected in Each Land Use Type.

\begin{tabular}{|c|c|c|c|c|c|c|c|c|c|c|c|c|}
\cline { 2 - 16 } & \multicolumn{4}{c|}{ Captures } & \multicolumn{4}{c|}{ Days with Detections } & \multicolumn{4}{c|}{$\begin{array}{c}\text { Occupied Sites } \\
\text { (Cameras) }\end{array}$} \\
\cline { 2 - 16 } & Ag & Dev & Res & Sum & Ag & Dev & Res & Sum & Ag & Dev & Res & Sum \\
\hline $\begin{array}{c}\text { Mountain } \\
\text { Lion }\end{array}$ & 0 & 0 & 11 & $\mathbf{1 1}$ & 0 & 0 & 9 & $\mathbf{9}$ & 0 & 0 & 9 & $\mathbf{9}$ \\
\hline Coyote & 6 & 3 & 45 & $\mathbf{5 4}$ & 6 & 3 & 37 & $\mathbf{4 6}$ & 2 & 1 & 14 & $\mathbf{1 7}$ \\
\hline Bobcat & 10 & 38 & 70 & $\mathbf{1 1 8}$ & 9 & 32 & 57 & $\mathbf{9 8}$ & 4 & 10 & 13 & $\mathbf{2 7}$ \\
\hline Grey Fox & 11 & 5 & 0 & $\mathbf{1 6}$ & 10 & 5 & 0 & $\mathbf{1 5}$ & 4 & 3 & 0 & $\mathbf{7}$ \\
\hline Raccoon & 16 & 67 & 0 & $\mathbf{8 3}$ & 16 & 53 & 0 & $\mathbf{6 9}$ & 7 & 13 & 0 & $\mathbf{2 0}$ \\
\hline Skunk & 7 & 108 & 19 & $\mathbf{1 3 4}$ & 7 & 49 & 11 & $\mathbf{6 7}$ & 4 & 9 & 6 & $\mathbf{1 9}$ \\
\hline Opossum & 9 & 80 & 0 & $\mathbf{8 9}$ & 9 & 36 & 0 & $\mathbf{4 5}$ & 6 & 6 & 0 & $\mathbf{1 2}$ \\
\hline Dog & 80 & 267 & 0 & $\mathbf{3 4 7}$ & 52 & 112 & 0 & $\mathbf{1 6 4}$ & 9 & 16 & 0 & $\mathbf{2 5}$ \\
\hline Cat & 104 & 391 & 0 & $\mathbf{4 9 5}$ & 54 & 178 & 0 & $\mathbf{2 3 2}$ & 10 & 19 & 0 & $\mathbf{2 9}$ \\
\hline Rabbit & 6 & 8 & 2 & $\mathbf{1 6}$ & 5 & 7 & 2 & $\mathbf{1 4}$ & 2 & 3 & 1 & $\mathbf{6}$ \\
\hline Unknown & 4 & 8 & 5 & $\mathbf{1 7}$ & 4 & 8 & 5 & $\mathbf{1 7}$ & 3 & 6 & 4 & $\mathbf{1 3}$ \\
\hline Deer & 0 & 126 & 287 & $\mathbf{4 1 3}$ & 0 & 85 & 175 & $\mathbf{2 6 0}$ & 0 & 17 & 27 & $\mathbf{4 4}$ \\
\hline Wild Pig & 0 & 0 & 12 & $\mathbf{1 2}$ & 0 & 0 & 11 & $\mathbf{1 1}$ & 0 & 0 & 8 & $\mathbf{8}$ \\
\hline $\begin{array}{c}\text { Ground } \\
\text { Squirrel }\end{array}$ & 9 & 6 & 24 & $\mathbf{3 9}$ & 7 & 5 & 11 & $\mathbf{2 3}$ & 3 & 2 & 4 & $\mathbf{9}$ \\
\hline Jackrabbit & 4 & 2 & 0 & $\mathbf{6}$ & 4 & 2 & 0 & $\mathbf{6}$ & 2 & 1 & 0 & $\mathbf{3}$ \\
\hline
\end{tabular}




\section{Discussion}

This study explored how carnivore species diversity, occupancy and distribution differed in proximity to developed, agricultural, and oak woodland (Reserve) land use areas. The apex predator for this study was the mountain lion, which was only found in the protected Reserve land use area. These results are in line with similar studies (Crooks, 2002; Ordeñana et al., 2010; Wang et al., 2015) that found that mountain lions prefer large patches of wild open space and are rarely detected in human-altered landcover types such as urban and agricultural development. Previous studies (Ordeñana et al., 2010; Dickson, Jenness, \& Beier, 2005) also show that mountain lions prefer native vegetation with vertical cover, findings which are consistent with this study's results showing mountain lions preferred to stay in the protected woodland Reserve. Mountain lions are solitary ambush predators that prefer to stay hidden within the cover of a tree's canopy, which could be a primary reason why they preferred mixed riparian habitats within the Reserve in this study.

One of the main goals of this research project was to determine the effects that apex predators had on mesopredators. Results from this study show that mountain lion presence was positively correlated to coyote occupancy. Koehler \& Hornocker (1991) also found that coyotes' use of habitat and prey overlapped with the mountain lions. However, I found that coyote activity times in the Reserve were highest in the morning (6am-12pm), when mountain lion activity times were lowest. The coyote activity pattern could be due to temporal niche partitioning in which coyotes avoided mountain lions to reduce their chance of being injured or killed. Temporal niche partitioning between 
carnivore species is used by subordinate species to avoid direct interaction with apex predators, and thus risk being killed by a dominant species (Wang et al., 2015). Grey foxes were not found at sites where mountain lion were detected, which was in oak woodland habitat. Since studies have found that grey foxes prefer oak woodland to developed land cover (Ordeñana et al., 2010; Riley et al., 2006), grey foxes may have been avoiding conflict with the larger predator to increase its chance at survival by avoiding the Reserve. Thus, grey fox may be exhibiting spatial and temporal niche partitioning. These findings are contrary to the study by Wang et al. (2015) which found grey foxes were detected more often at sites occupied by mountain lions. Ordeñana et al. (2010) and Riley et al. (2006) also found grey foxes to be tolerant of developed areas, which is supported by this study. More extensive research into niche partitioning is required to make definitive assumptions about the temporal activity patterns of this mesopredator species.

One of the other main goals of this research project was to determine how land use types affect the occupancy of mesopredator species. Results from this research determined bobcats and coyotes were much more likely to be detected in developed areas and in the Reserve rather than in agricultural land use types. As there were no mountain lions detected in the agricultural and developed land use types, coyote and bobcats became the dominant predator species in these land use types. Previous studies have found that coyotes and bobcats can exploit urban land use types because of their ability to highly adapt to different environments, exploit similar prey species, tolerate human disturbances, and use human-related food subsidies (Crooks 2002; Fedriani et al. 2001; 
Ordeñana et al., 2010; Riley et al. 2003). Results from this study show that coyote presence was positively correlated to bobcat and domestic cat occupancy. This result was expected given previous research (Fedriani Fuller, Sauvajot, \& York, 2000; Wang et al., 2015) that showed coyotes and bobcats can coexist in close spatial and temporal proximity to one another due to their similar adaptability to various habitat types, similarity of prey species, as well as their relative tolerance of human disturbance. Coyotes and bobcats may be exhibiting an increase in distribution and abundance due to the release from predation and competition by the apex predator, the mountain lion, as predicted by the mesopredator release hypothesis (Cove et al., 2012; Crooks \& Soule, 1999). Skunk, opossum, raccoon and grey fox may also benefit from the lack of an apex predator. In fact, skunks, opossums and raccoons showed the greatest frequency of detection in the developed land use compared to the Reserve and agricultural land use types, showing their tolerance of exurban landscapes (Bateman \& Fleming, 2012; Crooks, 2002; Hadidian, Prange, Rosatte, Riley, \& Gehrt, 2010). This result suggests that these mesopredator species are successfully able to take advantage of human-altered landscapes for their own advantage. Bateman \& Fleming (2012) state "Medium-sized carnivores such as raccoon, and striped skunk not only survive in cities but also have managed to exploit anthropogenic food sources and shelter to their significant advantage, achieving higher population densities than are found under natural conditions". Mesopredators within these human-altered landscapes can increase predation pressure on native prey species, which can lead to decreased biodiversity and population declines of 
small prey animals (Courchamp et al., 1999; Crooks \& Soule, 1999). The effect of prey species on mesopredators in these land uses was not included in this research.

Examining detections in the habitat types included in this study showed that all carnivore species, with the exception for opossums and skunks, were more likely to be found in riparian habitats, including mixed riparian forest and willow riparian forest/scrub, than any other habitat type. Thus, the riparian zone in each of the land use types was an extremely important habitat area, especially the developed and agricultural land use types. This finding stresses the need to protect, conserve and restore riparian habitats as a key to managing for the preservation of native carnivore species. 


\section{Recommendations}

This study adds to the global body of knowledge that documents how large and medium-sized carnivore species adapt and coexist with increasing human development, which can threaten carnivore communities. This research and previous studies (Crooks et al., 2011; Ordeñana et al., 2010; Ripple et al., 2014) have found that large mammalian species, such as mountain lions, need vast open spaces with minimal human disturbance to maximize their fitness potential. This requirement stresses the need to protect and create more open space preserves and provide connections between large habitat areas which can serve as a place for wildlife to thrive. Such management activities are especially important as urban and agricultural development can directly impact the occupancy and distribution of apex predators with cascading affects on mesopredators as well as the rest of the natural environment (Wang et al., 2015). One aspect of this research was to include a riparian component into the study design. Results show that maintaining a large, healthy and sustainable riparian habitat is critically important to the survival of all wildlife species, including native carnivores, both now and in the future.

One limitation of this research was the small sample size of the elusive carnivore species that were being studied. During the study there not enough photographic captures of a few carnivore species to run occupancy models and ultimately answer important research questions regarding how apex predators affected mesopredators. Future research should conduct multiple field seasons in larger areas. Including human beings into the study design and analysis is also recommended for future research. Adding humans into the analysis would enable a better understanding of how carnivore species 
react to human presence, in addition to land use types. This study shows occupancy models to be a useful tool to study how species interact with one another. This modeling software can be used to expand sample size and ultimately increase the body of knowledge of mammalian carnivore species interactions, as well as landscape level ecology discussed at length in this paper. This paper can be used as a baseline study for the affects that land use conversion can have on the occupancy and distribution of mammalian carnivore species. 


\section{Literature Cited}

Bateman, W., Fleming, A., (2012). Big city life: carnivores in urban environments. J. Zool. 287, 1-23.

Berger, J., Stacey, P.B., Bellis, L., \& Johnson, M.P. (2001). A mammalian predator-prey imbalance: grizzly bear and wolf extinction affect avian neotropical migrants. Ecol. Appl., 11, 947-960.

California Department of Fish and Wildlife biogeographic and information and observation system's (BIOS) website. (2015, April 3). Retrieved from https://map.dfg.ca.gov/bios

Ceballos, G., \& Ehrlich, P. (2002). Mammal population losses and the extinction crisis. Science. 27:597-623.

Census of Population and Housing. (2015, June 4). Retrieved from https:// Census.gov.

Courchamp, F., Langlais, M., \& Sugihara, G. (1999). Cats protecting birds: modeling the mesopredator release effect. Journal of Animal Ecology, 68, 282-292.

Cove, M., V., Jones B., M., Bossert, A., J., Dunwoody, R., K., White, B., C., \& Jackson, V., L. (2012). Use of camera traps to examine the mesopredator release hypothesis in a fragmented midwestern landscape. The American Midland Naturalist, 168(2):456-465.

Creel, S., \& Creel, N.M. (2002). The African wild dog: Behavior, ecology and conservation. Princeton University Press, Princeton, New Jersey.

Crooks, K. (2002). Relative sensitivities of mammalian carnivores to habitat fragmentation. Conservation Biology. Volume 16, Issue 2, pages 488-502, April 2002.

Crooks, K., Burdett, C., Theobald, D., Rondinini, C., \& Boitani, L. (2011). Global patterns of fragmentation and connectivity of mammalian carnivore habitat. Philosophical Transactions of the Royal Society. Biological Science Journal.

Crooks, K., \& Soule, M., E. (1999). Mesopredator release and avifaunal extinctions in a fragmented system. Nature. Vol. 400 Issue 6744, p563.

Defenders of Wildlife. (2017, September 4). Retrieved from http://www.defenders.org/mountain-lion/basic-facts

Dickson, B., Jenness, G., \& Beier, P. (2005). Influence of vegetation, topography, and roads on cougar movement in southern California. Journal of Wildlife Management 69:264276. 
Fedriani, J.M., Fuller, T.K., Sauvajot, R.M., \& York, E.C. (2000). Competition and intraguild predation among three sympatric carnivores. Oecologia 125, 258- 270.

Forman, R. (2003). Road Ecology: Science and Solutions. Island Press

Frid, A., Baker, G., \& Dill, L. (2008). Do shark declines create fear-released systems? Oikos. Volume 117, Issue 2, pages 191-201.

Gompper, M.E., Kays, R.W., Ray, J.C., Lapoint, S.D., Bogan, D.A., \& Cryan, J.R. (2006). A comparison of noninvasive techniques to survey carnivore communities in northeastern North America. Wildlife Soc. Bull. 34, 1142-1151.

Hadidian, J., Prange, S., Rosatte, R., Riley, D., \& Gehrt, D. (2010). Racoons (Procyon lotor). In Urban carnivores: 35-47. Gehrt, S.D., Riley, S.P.D. \& Cypher, B.L. (Eds). Baltimore, MD: The John Hopkins University Press.

Hardin, G. (1960). The competitive exclusion principle. Science. 131: 1292-1297.

Hutchinson, G.E. 1957. Concluding remarks. Cold spring harbor symposium on quantitative biology 22:415-427. International Union for Conservation and Nature.

Homer, G., Dewitz, A., Yang, L., Jin, S., Danielson, P., Xian, G., Coulston, J., Herold, D., Wickham, D., \& Megown, K. (2015). Completion of the 2011 national land cover database for the conterminous United States-representing a decade of land cover change information. Photogrammetric Engineering and Remote Sensing, v. 81, no. 5, p. 345-354

International Union for Conservation and Nature. (2015, March 14). The IUCN Red List of Threatened Species, Version 2015.2.

Johnson, C., Isaac, J., \& Fisher, D. (2007). Rarity of a top predator triggers continent-wide collapse of mammal prey: dingoes and marsupials in Australia. Proceedings of the Royal Society, 274 1608: 341-346.

Kasey, J. (2008). A photographic survey of mammalian trail use in Big Basin Redwood State Park. Master's Theses. San Jose State University. Paper 3499.

Kelly, M., \& Holub, M. (2008). Camera trapping of carnivores: Trap success among camera types and across species, and habitat selection by species, on salt pond mountain, Giles County, Virginia Northeastern Naturalist, 15(2):249-262.

Koehler, G., \& Hornocker, M. (1991). Seasonal resource use among mountain lions, bobcats, and coyotes. Journal of Mammalogy. Vol. 72, No. 2. pp. 391-396. 
Lynda, A., \& Yunger, A. (2006). Carnivore occurrence along an urban-rural gradient: A landscape-level analysis. Journal of Mammalogy, 87(6):1154-1164.

Miller, B., Dugelby, B., Foreman, D., Martinez, C., Noss, R., Phillips, M., Reading, R., Soulé, M., Terborgh T., \& Willcox, L. (2001) "The importance of large carnivores to healthy ecosystems," Endangered Species Update Vol. 18

National Oceanic and Atmospheric Administration Online Weather Data. (2014, May 10). Retrieved from https://www.ncdc.noaa.gov/cdo-web/

Noss, R., Quigley, H., Hornocker, M., Merrill, T., \& Paquet, P. (1996). Conservation biology and carnivore conservation in the Rocky Mountains. Conservation Biology. 10:949-963.

Ordeñana, M., Crooks, K., Boydston, E., Fisher, R., Lyren, L., Siudyla, S., Haas, C., Harris, S., Hathaway, S., Turschak, G., Keith, M., \& Van Vuren, D. (2010). Effects of urbanization on carnivore species distribution and richness. Journal of Mammalogy, 91(6):1322-1331.

Prugh, L., Stoner, C., Epps, C., Bean, W., Ripple W., Laliberte, A., \& Brashares, J. (2009). The rise of the mesopredator. BioScience. Vol. 59 No. 9.

Riley, D., Sauvajot, M., Fuller, K., York, C., Kamradt, A., Bromley, C., \& Wayne, T. (2003). Effects of urbanization and habitat fragmentation on bobcats and coyotes in southern California. Conserv. Biol. 17, 569.

Riley D., Pollinger P., Sauvajot M., York C., Bromley C., Fuller K., \& Wayne K. (2006). A southern California freeway is a physical and social barrier to gene flow in carnivores. Molecular Ecology 10:1-9.

Ripple, W., \& Beschta, R. (2005). Linking wolves and plants. Aldo Leopold on Trophic Cascades. BioScience. Pg. 613-621.

Ripple, W., \& Beschta, R. (2006). Linking a cougar decline, trophic cascade, and catastrophic regime shift in Zion National Park. Biol. Conserv. 133 , $397-408$.

Ripple, W., Estes, J., Robert L. Beschta, R., \& Wilmers, C. (2014). Status and ecological effects of the world's largest carnivores. Science Magazine.

Roemer, G., Gompper, M., \& Valkenburgh, B. (2009). The ecological role of the mammalian mesocarnivore. BioScience. Vol. 59 No. 2.

Sanderson, E. W. (2002). The human footprint in central California. BioScience,52(10), 891904. 
Schuette, P., Wagner P., Wagner M., \& Creel, S. (2013). Occupancy patterns and niche partitioning within a diverse carnivore community exposed to anthropogenic pressures. Biological Conservation. 301-312.

Soulé M., Bolger D., Alberts A., Wright I., Sorice M., \& Hill S. (1988). Reconstructed dynamics of rapid extinctions of chaparral requiring birds in urban habitat islands. Conservation Biology 2: 73-91.

Terborgh, J. (1999) "The role of top carnivores in regulating terrestrial ecosystems," Chapter 3 in Continental conservation

Townsend, S. (2013). Wildlife camera studies at Pepperwood. A Dwight Center for Conservation Science- technical report. 2013.

Wang, Y. (2014). Using novel technologies to confront challenges in predator conservation, community ecology, and citizen science. UC Santa Cruz: Environmental Studies. Retrieved from: https://escholarship.org/uc/item/4zs0r7np

Wang, S., \& Macdonald, D. (2009). Feeding habits and niche partitioning in a predator guild composed of tigers, leopards and dholes in a temperate ecosystem in central Bhutan. Journal of Zoology. 275-283.

Wang, Y., Allen M., \& Wilmers, C. (2015). Mesopredator spatial and temporal responses to large predators and human development in the Santa Cruz Mountains of California. Biological Conservation 190 (2015) 23-33.

U.S. Department of Agriculture Wildlife Service (2008). Retrieved from https://awionline.org/awi-quarterly/2009-fall/carnivore-management-u-s-need-reform

Zimmermann, A., Baker, N., Inskip, C., Linnell, J., Marchini, S., Odden, J., Rasmussen, G., \& Treves, A. (2009). Wild rangelands: Conserving wildlife while maintaining livestock in semi-arid ecosystems. Chapter 6: Contemporary views of human-carnivore conviction wild rangelands. 